Süleyman Demirel Üniversitesi Fen Edebiyat Fakültesi Fen Dergisi

Atıf için / For Citation: S. Akay, "Ultrasonik Ortamda Biyokömür Kullanarak Sulu Çözeltiden 5-Florourasilin Giderilmesi: Yanıt Yüzey Modellemesi ve Optimizasyonu”, Süleyman Demirel Üniversitesi Fen Edebiyat Fakültesi Fen Dergisi, 15(2), 264-286, 2020.

\title{
Ultrasonik Ortamda Biyokömür Kullanarak Sulu Çözeltiden 5-Florourasilin Giderilmesi: Yanıt Yüzey Modellemesi ve Optimizasyonu
}

\author{
Sema AKAY ${ }^{* 1}$

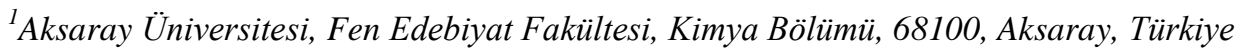 \\ *yazışılan yazar e-posta: sema.akay7@gmail.com
}

(Alınış / Received: 25.09.2020, Kabul / Accepted: 10.11.2020, Yayımlanma / Published: 29.11.2020)

Özet: Kemoterapide en çok reçete edilen aktif maddelerden biri olan ve atık su arıtma tesisi sahasında yaygın olarak bulunan 5-Florourasilin (5-FLU) adsorpsiyonu, kağıt çamuru ile buğday kabuklarından üretilen biyokömürle ultrasonik ortamda gerçekleştirilmiştir. Adsorbent olarak kullanılan biyokömür, SEM, EDX, BET, FT-IR ve XRF analizleri ile karakterize edilmiştir. Yanıt yüzey modellemesi ve Box-Behnken tasarımı kullanılarak optimum koşullar ile 5-FLU konsantrasyonu, adsorpsiyon zamanı ve adsorbent miktarı parametrelerinin etkileri araştırılmıştır. Adsorbent miktarı en etkili parametre olarak belirtilirken, optimum adsorpsiyon koşulları: konsantrasyon $=5,48 \mathrm{mg} / \mathrm{L}$, adsorbent miktarı $=1,61 \mathrm{~g}$, zaman $=39,61$ dakika olarak tahmin edilmiş ve bu şartlarda \% 95,99 oranında adsorpsiyon gerçekleşeceği belirlenmiştir. Langmuir izoterm modeli deneysel veriler için daha iyi bir uyum $\left(\mathrm{R}^{2}=0,999\right)$ göstermiş ve maksimum adsorpsiyon kapasitesi $\left(\mathrm{q}_{\max }\right)$, Langmuir izotermiyle gösterildiği gibi $5,75 \mathrm{mg} / \mathrm{g}$ olarak bulunmuştur. Kinetik olarak adsorpsiyon işlemi, kemisorpsiyonun hız sınırlayıcı adım olduğunu gösteren pseudo birinci derece model olarak belirlenmiştir.

Anahtar kelimeler: Adsorpsiyon, 5-Florourasil, Biyokömür, Ultrasonik, Box-Behnken tasarımı

\section{Removal of 5-Fluorouracil from Aqueous Solution Using Biochar in Ultrasonic Medium: Response Surface Modeling and Optimization}

\begin{abstract}
The adsorption of 5-Fluorouracil (5-FLU), one of the most prescribed active substances in chemotherapy and commonly found in wastewater treatment plant area, was achieved in ultrasonic medium on biochar produced from paper sludge and wheat husks. Biochar used as adsorbent was characterized by SEM, EDX, BET, FT-IR and XRF analyses. By using response surface modeling and Box-Behnken design, the optimum conditions and eff ects of 5-FLU concentration, adsorption time and adsorbent dosage parameters were investigated. The adsorbent was stated the most influential factor whereas the optimum adsorption conditions were predicted as: concentration $=5.48 \mathrm{mg} / \mathrm{L}$, adsorbent dosage $=1.61 \mathrm{~g}$, adsorption time $=$ $39.61 \mathrm{~min}$, and was determined that adsorption would occur at a rate of $95.99 \%$ at these conditions. The Langmuir isotherm model provided a better fit $\left(\mathrm{R}^{2}=0.999\right)$ for the experimental data and that maximum adsorption capacity $\left(\mathrm{q}_{\max }\right)$ was found $5.75 \mathrm{mg} / \mathrm{g}$ as indicated by the Langmuir isotherm. Kinetically, the adsorption process determined a pseudo-first order model, indicating that chemisorption was the rate-limiting step.
\end{abstract}

Keywords: Adsorption, 5-Fluorouracil, Biochar, Ultrasonic, Box-Behnken design 


\section{Giriş}

İlaçlar; ilaç endüstrisinden, hastanelerden ve belediye atık su arıtma tesislerinden gelen atık maddelerin deşarjı nedeniyle çeşitli su ortamlarında bulunan, düzenlemeye tabi olmayan eser miktardaki organik kirleticilerdir $[1,2]$. Bu kirleticiler arasında sitostatik ilaçlar, kanserojen, mutajenik ve teratojenik bileşikler olarak sınıflandırılmaları nedeniyle büyük ilgi gören ve çevre kirleticilerin yeni tanınan bir sınıfıdır. Kemoterapide yaygın olarak kullanılan bu ilaçlar, yüksek tüketim oranları, insanlara ve çevreye olan olumsuz etkileri ve atık su arıtma tesislerinde düşük oranlarda bertaraf edilmeleri nedeniyle çevresel kaygılara sebep olmaktadır $[3,4]$.

Sitostatik, antikanser, sitotoksik ve antineoplastik terimleri eşanlamlı olup Anatomik Terapötik Kimyasal Sınıflandırma (ATC) şemasında sitostatik ilaçlar, etki tarzlarına göre alkilleyici ajanlar, antimetabolitler, bitki alkaloidleri ve diğer doğal ürünler, sitotoksik antibiyotikler ve diğer antineoplastik maddeler olmak üzere beş sınıfa ayrılmaktadır [5,6]. 5-Florourasil (5-FLU), pirimidin analogları olarak bilinen antimetabolit sınıfi bir ilaç olup kolon kanseri, rektum kanseri, mide kanseri, meme kanseri, yumurtalık kanseri, mesane kanseri, cilt kanseri, karaciğer kanseri gibi katı tümörlerin tedavisinde yaygın kullanılan bir antikanser ajandır [7]. 5-FLU, son zamanlarda farklı su bölmelerinde ve özellikle hastane ve belediye atık sularında ng/L ile $\mu \mathrm{g} / \mathrm{L}$ arasında değişen konsantrasyonlarda tespit edilmiştir [8]. Biyolojik bozunmaya karş1 5-FLU'nun yüksek direnci, su matrislerinde bulunan askıda katı maddelere düşük adsorpsiyonu ve çok düşük buhar basıncı, bu ilacın sulu ortamda son derece kalıcı olacağını düşündürmüştür [9]. Bununla birlikte, atık su arıtma süreçleri sırasında bunların uzaklaştırma etkinliklerinin, hem bileşiklerin fizikokimyasal özelliklerine hem de uygulanan arıtma işlemine bağlı olarak önemli ölçüde değiștiği tespit edilmiştir. Zayıf biyolojik bozunma ve geleneksel atık su arıtma yöntemleriyle düşük giderim veriminden dolayı, bu ilaçların başarılı bir şekilde ortamdan uzaklaştırılması için alternatif yöntemler geliştirilmiştir. $\mathrm{Bu}$ anlamda, membran filtreleme, adsorpsiyon, ozonlama, biyomembran filtreleme ve Fenton reaksiyonu, fotodegradasyon ve elektrokimyasal oksidasyon gibi ileri oksidasyon süreçlerini içeren gelişmiş arıtma yöntemleri, sitostatik ilaçları içeren su ve atık suyun arıtılması için umut verici bir teknoloji oluşturmuştur [4]. Yukarıda belirtilen işlemlerin mevcudiyetine rağmen, adsorpsiyon hala evrensel doğası, ucuzluğu, kullanım kolaylığı, esnekliği, toksik kirletici maddelere karşı duyarsızlığı ve yüksek verimliliği ile etkinliği açısından en iyisidir ve suyun yeniden kullanımı için genellikle avantajlıdır. Ayrıca, adsorpsiyon, tehlikeli yan ürünler oluşturmadan çözünür ve çözünmez organik kirleticileri de ortadan kaldırabilmektedir [10-12].

Karbonlu malzemeler, toprak ve sudaki organik ve inorganik kirleticilerin adsorpsiyonunda sorbent olarak uzun süredir kullanılmaktadır. Biyokömür, 200-900 ${ }^{\circ} \mathrm{C}$ arasındaki sıcaklıklarda oksijensiz veya çok az oksijen içeren ortamda, biyokütlenin termokimyasal ayrışması (piroliz) sırasında üretilen gözenekli, karbonlu bir malzemedir. En önemli avantajı, tarımsal ürün artıkları, kanalizasyon çamuru ve gübre gibi çeşitli biyokütle malzemesinden üretilebilmesi ve bu anlamda hammadde miktarının bol olmasıdır. Özelliklerini kontrol eden temel parametreler arasında piroliz sıcaklığı, işlem süresi, 1sı transfer hızı ve hammadde türü bulunmaktadır. Biyokömürün kirletici madde yönetimindeki etkinliği yüzey alanına, gözenek boyutu dağılımına ve iyon değiştirme kapasitesine bağlıdır. Nispeten yüksek piroliz sıcaklıkları genellikle yüzey alanını, mikrogözenekliliği ve hidrofobikliği artırarak organik kirleticilerin uzaklaştırılmasında etkili olan biyokömürler üretmektedir. Düşük sıcaklıklarda elde edilen biyokömürler de, 
oksijen içeren fonksiyonel grupları, elektrostatik çekme ve çökeltme ile inorganik / polar organik kirleticileri uzaklaştırmak için daha uygun olmaktadır. Bu anlamda, geniş spesifik yüzey alanı, gözenekli yapısı ve bol fonksiyonel grupları gibi üstün özellikleri sayesinde, biyokömür, suların iyileştirilmesi için düşük maliyetli, etkili ve çevre dostu bir sorbent olarak görünmektedir [13-15].

Adsorpsiyon yönteminde, adsorbentlerin kirleticileri uzaklaştırma verimini arttırmak için proses değişkenlerinin ve bunların adsorpsiyon kapasitesi üzerindeki etkilerinin değerlendirilmesi istenmektedir. Bunun için proses değişkenlerinin optimizasyonuna ihtiyaç vardır ve bu da geleneksel yaklaşımla çok pahalı ve zaman alıcı olan çok sayıda deneyin yapılmasını gerektirmektedir [16]. Son zamanlarda, çok değişkenli kimyasal proses optimizasyonunda birkaç deneysel tasarım yöntemi kullanılmıştır ve yanıt yüzey modellemesi (RSM) bu tasarım yöntemlerinden biridir. RSM, karmaşık etkileşimlerin varlığında bile yanıtları aynı anda değiştirerek ve sınırlı sayıda deney gerçekleştirerek etkileyen birkaç değişkenin etkisini değerlendirmede, prosesleri geliştirmede ve optimize etmede kullanılan matematiksel ve istatistiksel teknikler topluluğudur. Temel amacı, adsorpsiyon işleminin optimum koşullarını ve/veya çalışma koşullarını elde etmektir. Deneyleri tasarlamak için merkezi bileşik tasarım (CCD), Box-Behnken tasarımı (BBD), Plackett - Burman tasarımı (PB) veya faktöriyel tasarım kullanılmaktadır $[12,17,18]$.

Literatürde adsorpsiyon süreci için deneysel tasarım ve optimizasyon yaklaşımını kullanan çalışmalar mevcuttur [16-20] ancak 5-FLU adsorpsiyonunun optimizasyonu ile ilgili literatürde hiçbir bilgi bulunmamaktadır. Buna ek olarak, 5-FLU ve diğer sitostatik ilaçların kemoterapide oldukça fazla kullanılmasına ve düşük konsantrasyonlarda bile kanserojen, mutajenik, teratojenik, genotoksik ve sitotoksik etkilere sahip olmasına rağmen diğer farmasötiklere göre daha az ilgi gördüğü tespit edilmiştir [21]. Bu nedenle literatürde 5-FLU'nun adsorpsiyonu ile ilgili çok az çalışma yayınlanmıştır. Literatürdeki bu çalışmalardan biri Kovalova ve arkadaşları tarafindan [22], 5-FLU'nun ultra saf sudan ve bir atık su arıtma tesisi atığından uzaklaştırılması için yapılan çalışmadır. Burada 5-FLU'nun iki farklı toz aktif karbonla adsorpsiyonu gerçekleştirilmiştir. Çözelti pH'sı, iyonik kuvvet, sıcaklık ve atık organik maddenin 5FLU adsorpsiyonu üzerindeki etkileri değerlendirilmiş ve düşük $\mathrm{pH}$ değerlerinde daha yüksek adsorpsiyon kapasiteleri gözlenmiştir. Genel olarak sonuçlar, karbon dozlarının apolar adsorbatların \%90'dan fazlasını uzaklaştırmak için yeterli olduğu miktarda, polar adsorbat 5-FLU'nun \%50'sinden fazlasını uzaklaştıramadığını ve temas süresinin kritik bir parametre olduğunu göstermiştir. Adsorpsiyon yöntemi dışında ileri oksidasyon prosesleri de, 5-FLU gibi yüksek kimyasal stabiliteye ve düşük biyobozunurluğa sahip kirleticileri uzaklaştırmak için sıklıkla kullanılmış ancak kirletici konsantrasyonlarının çok düşük olduğu durumlarda pahalı bir yaklaşım olarak bildirilmiştir [23]. Bu nedenle, bu çalışma, biyokömür ile 5-FLU'nun adsorpsiyonu için yeni bir strateji sunmaktadır. Biyokömür bazlı malzemelerin de zararlı ilaç etken maddelerinin uzaklaştırılmasında büyük avantaj sağladığı belirtilmektedir [24]. Biyokömürün çevre kirliliğine sebep olan atıkların ortadan kaldırılmasına ek olarak çürümeye terk edilen biyokütle atıklarının değerlendirilmesine ve katma değeri yüksek ürünlere dönüştürülmesine de katkıda bulunduğu bildirilmektedir [25]. Bu anlamda sunulan bu çalışmada, kağıt çamuru ve buğday kabuklarından üretilen biyokömürle sulu çözeltiden 5-FLU adsorpsiyonu için basit bir yöntem geliştirilmiş ve maliyetli aktifleştirilmiş adsorbentler kullanılmamıştır. Buna ek olarak, deneysel tasarım ve optimizasyon için RSM kullanılarak BBD tasarım yöntemi ile deneylerin optimizasyon şartları belirlenmiş ve 5-FLU konsantrasyonu, 
adsorpsiyon zamanı ve adsorbent miktarı parametrelerinin etkileri değerlendirilmiştir. Son olarak, bilinen izoterm ve kinetik modelleri kullanılarak adsorpsiyon mekanizması ile adsorpsiyon kinetiği incelenmiş ve denge durumundaki adsorpsiyon kapasitesi belirlenmiştir.

\section{Materyal ve Metot}

Deneysel çalışmalarda kirletici olarak 5-FLU (Sigma/Aldrich) seçilmiş ve adsorpsiyon işlemi VWR (USC300TH) ultrasonik banyoda sabit $45 \mathrm{kHz}$ frekansta gerçekleştirilmiştir.

5-FLU'nun adsorpsiyonu sonunda elde edilen örneklerin kantitatif analizleri, Yüksek Performanslı Siv1 Kromatografisi (HPLC, Agilent 1290 Infinity)'nde Zorbax-SB C18 $(150 \times 4,6 \mathrm{~mm}, 5 \mu \mathrm{m})$ kolonu kullanılarak gerçekleştirilmiştir. Hareketli faz bileşimi su (\%1 asetik asit) (A) ve metanol (\%1 asetik asit) (B) olarak belirlenmiş ve izokratik elüsyon programı, 95:5 (A:B) şeklinde ayarlanmıştır. Örnekler enjeksiyon hacmi $10 \mu \mathrm{L}$, akış hızı 0,50 mL/dk ve dedektörün dalga boyu $277 \mathrm{~nm}$ olacak şekilde 3 tekrar ile analiz edilmiştir.

Optimum koşullarda 5-FLU'nun adsorpsiyonunu ölçmek için adsorbent olarak biyokömür kullanılmıştır. Kağıt çamuru ile buğday kabuğundan hazırlanan biyokömür, Sonnenerde $\mathrm{GmbH}$ (Riedlingsdorf, Avusturya) firmasından temin edilmiş ve herhangi bir işleme/modifikasyon olmadan alındığı gibi kullanılmıştır. Biyokömür, $500{ }^{\circ} \mathrm{C}$ de geleneksel piroliz yöntemiyle 20 dakikalık bir işlem süresinde PYREG 500 - III piroliz ünitesinde hazırlanmış ve pirolitik buharları uzaklaştırmak için yıkama gazı olarak hiçbir inert gaz kullanılmamıştır. Biyokömürden 5 dakika gaz çıkışına izin verilmiş ve biyokömür \%30 su içeriğine kadar su ile söndürülmüştür. Birkaç gün ortam şartlarında sonrasında $40{ }^{\circ} \mathrm{C}$ 'de kurutularak $5{ }^{\circ} \mathrm{C}$ 'nin altında hava geçirmeyecek şekilde saklanmıştır.

Biyokömürün karakterizasyonu için Taramalı Elektron Mikroskobu (SEM, Zeiss), Enerji dağıtıcı X-1şını spektroskopisi (EDX, Bruker), Barrett-Brunauer-Emmett-Teller (BET, Micromeritics), Fourier Dönüşümlü Kızı̈ötesi Spektroskopisi (FT-IR, Perkin Elmer) ve X-Işınları Floresans Spektroskopisi (XRF, Pan Analytical) kullanılmıştır. Biyokömürün morfolojik yapısı SEM ile karakterize edilmiş ve yüzey iletkenliğini arttırmak için analizden önce yüzeyi vakum altında elektro biriktirme yoluyla platin/paladyum ile kaplanmıştır. Biyokömürün spesifik yüzey alanı ve gözenek hacmi azot adsorpsiyon-desorpsiyon izotermine dayalı BET denklemi ile tahmin edilmiştir. Degaz portuna alınan biyokömür, 4 saat $90{ }^{\circ} \mathrm{C}$ 'de 20 saat $150{ }^{\circ} \mathrm{C}$ 'de degaz edilmiştir. Analiz $-196{ }^{\circ} \mathrm{C}$ de gerçekleştirilmiştir. Her analiz 10 saat sürmüş ve $\mathrm{p} / \mathrm{p}^{0}$ 0,01-1,0 arasında ölçüm gerçekleştirilmiş yüzey alanları BET izoterm formülü ile bilgisayar tarafından otomatik olarak hesaplanmıştır. Kimyasal bileşimi XRF kullanılarak belirlenmiştir. Adsorpsiyondan önce biyokömürün 4000-500 cm $\mathrm{cm}^{-1}$ bölgesinde zayıflatılmış toplam yansıma (ATR) tekniğiyle FTIR analizi gerçekleştirilmiştir. Adsorbentin yüzey kimyası, sıfır yük noktasının (pHpzc) pH'sı belirlenerek de incelenmiştir. Biyokömürün pHpzc'sini belirlemek için ilk olarak kullanılacak ultra saf suyun içerisinde çözünmüş karbondioksit 1sıtılarak uzaklaştırılmıştır. Ardından oda sicaklığına kadar soğutulan ultra saf su ile $50 \mathrm{~mL}$ 'lik 6 farklı balon jojede $0,01 \mathrm{M} \mathrm{NaCl}$ çözeltileri hazırlanmıştır. Çözeltilerin başlangıç pH'ları, 0,1 M NaOH ve $0,1 \mathrm{M} \mathrm{HCl}$ ilave edilerek $2,4,6,8,10$ ve 12 'ye ayarlanmıştır. $\mathrm{pH}$ ayarlaması yapılan her çözeltiye 
$0,15 \mathrm{~g}$ biyokömür eklenmiş ve oda sıcaklığında bir çalkalayıcıda 24 saat karıştırılmıştır. İşlemin ardından son pH değerleri ölçülmüştür [26].

\subsection{5-FLU adsorpsiyon yöntemi}

Deneysel tasarım ve optimizasyon için RSM kullanılmış olup BBD yöntemi (Design Expert 9.0.6, Stat-Ease Inc.) ile deneylerin optimizasyon şartları belirlenmiştir. Adsorbent miktarı, deney zamanı, konsantrasyon gibi parametreler deneysel faktör olarak seçilmiş ve 5-Florourasilin adsorpsiyon çalışmaları, geliştirilen deneysel tasarıma (Tablo 2) göre gerçekleştirilmiştir. Tüm deneylerde konsantrasyon 5-25 mg/L, deney süresi 15-60 dakika aralığında tutulmuş ve ultrasonik banyoda 0,5-2,0 g arasında değişen adsorbent miktarı ile $50 \mathrm{~mL}$ 5-Florourasil çözeltisi kullanılarak adsorpsiyon işlemleri tamamlanmıştır. Ardından alınan örnekler HPLC'de analiz edilmiş ve son konsantrasyonlar ile \% adsorpsiyon verimi hesaplanmıştır (Denklem 1).

$$
\% \text { Adsorpsiyon }=\frac{\mathrm{C}_{0}-\mathrm{C}_{e}}{\mathrm{C}_{0}} \times 100
$$

Burada $\mathrm{C}_{0}$ ve $\mathrm{Ce}$, sırasıyla $\mathrm{mg} / \mathrm{L}$ cinsinden 5-FLU'nun başlangıç ve denge konsantrasyonunu ifade etmektedir. Adsorpsiyonda ultrasonik ses dalgalar1 kullanmanın, adsorbent yüzeyinde bir dizi hızlandırılmış kimyasal reaksiyon ve kütle transferi ile adsorpsiyon verimliliğini artırdığı belirtilmiştir [19,27,28].

\subsection{Deneysel tasarım ve optimizasyon}

Adsorpsiyon süreci Box-Behnken tasarım yöntemi ile optimize edilmiş ve sonuçların istatistiksel analizi RSM ile yapılmıştır. Deneysel tasarımda kullanılan üç bağımsız değişken ve bunların aralık ve seviyeleri Tablo 1'de gösterilmiştir. Burada incelenmiş olan her bir parametre için en düşük, orta ve en yükssek değerler sırasıyla $(-1,0$ ve +1$)$ olarak kodlanmıştır.

Tablo 1. 5-Florourasil için Bağımsız Değişkenler ile Deneysel Aralık ve Seviyeleri

\begin{tabular}{ccccc}
\hline \multirow{2}{*}{ Değiş̧kenler } & \multirow{2}{*}{ Faktör } & \multicolumn{3}{c}{ Aralık ve Seviye } \\
& & $\mathbf{- 1}$ & $\mathbf{0}$ & $\mathbf{+ 1}$ \\
\hline Konsantrasyon $(\mathrm{mg} / \mathrm{L})$ & $\mathrm{X}_{1}$ & 5 & 15 & 25 \\
\hline Zaman $(\mathrm{dk})$ & $\mathrm{X}_{2}$ & 15 & 37,5 & 60 \\
\hline Adsorbent $(\mathrm{g} / \mathrm{L})$ & $\mathrm{X}_{3}$ & 0,5 & 1,25 & 2,0 \\
\hline
\end{tabular}

5-Florourasilin biyokömür ile adsorpsiyonu için geliştirilen deneysel tasarım Tablo 2'de verilmiştir. $\mathrm{Bu}$ deneysel tasarım, Design Expert 9.0.6 modeli bilgisayar yazılımı ile oluşturulmuş ve toplamda 17 farklı deney seti elde edilmiştir.

Tablo 2. 5-Florourasil için Box-Behnken Deneysel Tasarım Modeli

\begin{tabular}{cccc} 
Deney No Konsantrasyon (mg/L) & Zaman (dk) & Adsorbent $(\mathbf{g})$ \\
\hline 1 & 5 & 15 & 1,25 \\
2 & 25 & 15 & 1,25 \\
3 & 5 & 60 & 1,25 \\
4 & 25 & 60 & 1,25 \\
5 & 5 & 37,5 & 0,5 \\
6 & 25 & 37,5 & 0,5 \\
7 & 5 & 37,5 & 2 \\
\hline
\end{tabular}


Tablo 2. 5-Florourasil için Box-Behnken Deneysel Tasarım Modeli (Devamı)

\begin{tabular}{cccc}
\hline Deney No Konsantrasyon (mg/L) & Zaman (dk) & Adsorbent $(\mathbf{g})$ \\
8 & 25 & 37,5 & 2 \\
9 & 15 & 15 & 0,5 \\
10 & 15 & 60 & 0,5 \\
11 & 15 & 15 & 2 \\
12 & 15 & 60 & 2 \\
13 & 15 & 37,5 & 1,25 \\
14 & 15 & 37,5 & 1,25 \\
15 & 15 & 37,5 & 1,25 \\
16 & 15 & 37,5 & 1,25 \\
17 & 15 & 37,5 & 1,25 \\
\hline
\end{tabular}

Her bir deney 3 tekrarla çalışılmış ve sonuçların aritmetik ortalaması alınarak aşağıda verilen denkleme (Denklem 2) benzer bir lineer denklem oluşturulmuştur.

$Y=\beta_{0}+\beta_{1} x_{1}+\beta_{2} x_{2}+\beta_{3} x_{3}+\beta_{12} x_{1} x_{2}+\beta_{13} x_{1} x_{3}+\beta_{23} x_{2} x_{3}+\beta_{11} x_{1}^{2}+\beta_{22} x_{2}^{2}+\beta_{33} x_{3}^{2}$

Burada $Y$, öngörülen yanıtı; $\beta_{0}$, sabit katsayıyı; $\beta_{1}, \beta_{2}$ ve $\beta_{3}$ doğrusal katsayıları; $\beta_{11}, \beta_{22}$ ve $\beta_{33}$ ikinci dereceden katsayıları; $\beta_{12}, \beta_{13}$ ve $\beta_{23}$ etkileşim katsayılarını ve $x_{1}, x_{2}$ ve $x_{3}$ bağımsız süreç değişkenlerini ifade etmektedir. Ayrıca, denklemdeki pozitif işaret, değişkenlerin sinerjistik etkisini gösterirken, negatif işaret değişkenlerin antagonistik etkisini temsil etmektedir [12].

Denklem 2'de yer alan her ikili ve ikinci dereceden terimin Y yanıtı üzerindeki etkisi, varyans analizi (ANOVA) ile belirlenmiştir. Model denklemde, bir değişken sabit tutularak üç boyutlu (3D) yüzey grafikleri çizilmiştir. Önerilen modeli doğrulamak için, deneysel giderim verimlilikleri karşılaştırılmıştır (Tablo 6). Son olarak, maksimum 5FLU giderimi için optimum adsorpsiyon koşulları belirlenmiştir.

\section{Bulgular}

\subsection{Biyokömürün karakterizasyonu}

Biyokömürün üretim koşulları ile fiziksel ve kimyasal özellikleri Tablo 3'te listelenmiştir [20]. Biyokömürün tam karakterizasyonu Bachmann ve arkadaşları [29] tarafından gerçekleştirilen çalışmada da gösterilmiştir.

Tablo 3. Biyokömürün Karakterizasyonu ve 5-Florourasilin Fizikokimyasal Özellikleri

\begin{tabular}{cc}
\hline & Biyokömür \\
\hline Piroliz sıcaklığ $1{ }^{\circ} \mathrm{C}$ & 500 \\
İşlem süresi/dk & 20 \\
Toplam C $(\%)$ & 50,5 \\
$\mathrm{H}(\%)$ & 1,55 \\
$\mathrm{~N}(\%)$ & 1,29 \\
$\mathrm{O}(\%)$ & 6,4 \\
$\mathrm{O} / \mathrm{C}$ oranı & 0,126 \\
$\mathrm{Kül}$ içeriği $(\%)$ & 40,2 \\
$\mathrm{P}(\mathrm{mg} / \mathrm{kg})$ & 6610 \\
$\mathrm{~K}(\mathrm{mg} / \mathrm{kg})$ & 16800 \\
$\mathrm{Na}(\mathrm{mg} / \mathrm{kg})$ & 910 \\
$\mathrm{Mg}(\mathrm{mg} / \mathrm{kg})$ & 4530
\end{tabular}


Tablo 3. Biyokömürün Karakterizasyonu ve 5-Florourasilin Fizikokimyasal Özellikleri (Devamı)

\begin{tabular}{cc}
\hline & Biyokömür \\
\hline $\mathrm{Mn}(\mathrm{mg} / \mathrm{kg})$ & 127 \\
$\mathrm{Ca}(\mathrm{mg} / \mathrm{kg})$ & 89200 \\
$\mathrm{Fe}(\mathrm{mg} / \mathrm{kg})$ & 2780 \\
$\mathrm{pH}$ & 8,3 \\
İletkenlik $(\mu \mathrm{S} / \mathrm{cm})$ & 759 \\
Yüzey alanı $\left(\mathrm{m}^{2} / \mathrm{g}\right)$ & 63,8 \\
\hline & $\mathbf{5 - F L U}$ \\
\hline Kimyasal formül & $\mathrm{C}_{4} \mathrm{H}_{3} \mathrm{FN}_{2} \mathrm{O}_{2}$ \\
Molar kütle $(\mathrm{g} / \mathrm{mol})$ & 130,08 \\
LogK $_{\mathrm{ow}}$ & $-0,89$ \\
$\mathrm{pK}$ & 8,02 \\
Çözünürlük $(\mathrm{g} / \mathrm{L})$ & 11,1 \\
\hline
\end{tabular}

Tablo 3 incelendiğinde, biyokömürün yüksek konsantrasyonlarda $\mathrm{Ca}, \mathrm{K}, \mathrm{P}$ ve $\mathrm{Mg}$ içerdiği tespit edilmiştir. Benzer şekilde, kül içeriği de \%40,2 olarak bulunmuştur. Bu durumun hammadde içeriğindeki inorganik bileşenlerin miktarının ve biyokömür veriminin bir göstergesi olduğu belirtilmiștir. Literatür verilerinde, yüksek piroliz sıcaklığının biyokömürün yüzey alanını ve hidrofobikliğini arttırdığı belirtilmiştir [10]. Aynı eğilim bu biyokömür üretiminde de gözlemlenmiş ve yüzey alanı $63,8 \mathrm{~m}^{2} / \mathrm{g}$ olarak belirlenmiştir. Yüksek piroliz sıcaklığına ek olarak, $\mathrm{O} / \mathrm{C}$ oranının da biyokömür yüzey hidrofobikliğinin bir göstergesi olduğu bildirilmiştir. $\mathrm{O} / \mathrm{C}$ oranı ne kadar düşükse, karbonlaşma derecesi o kadar yükselmekte ve biyokömür aromatik ve hidrofobik özellik kazanmaktadır $[10,30]$. Karakterizasyon sonuçlarında toplam $C$ değerinin \% $\% 50,5$ olması da bu durumu desteklemiştir.

Biyokömürün morfolojik yapısını incelemek için yapılan SEM analizinin sonuçları Şekil 1'de verilmiştir. Adsorpsiyon öncesinde (a) yüzeyin pürüzlü ve partikül boyutunun ortalama 28-30 nm (b) olduğu gözlenmiştir. Adsorpsiyon sonrasında (c) yüzeyin daha düzgün ve homojen dağılım gösterdiği belirlenmiştir. 


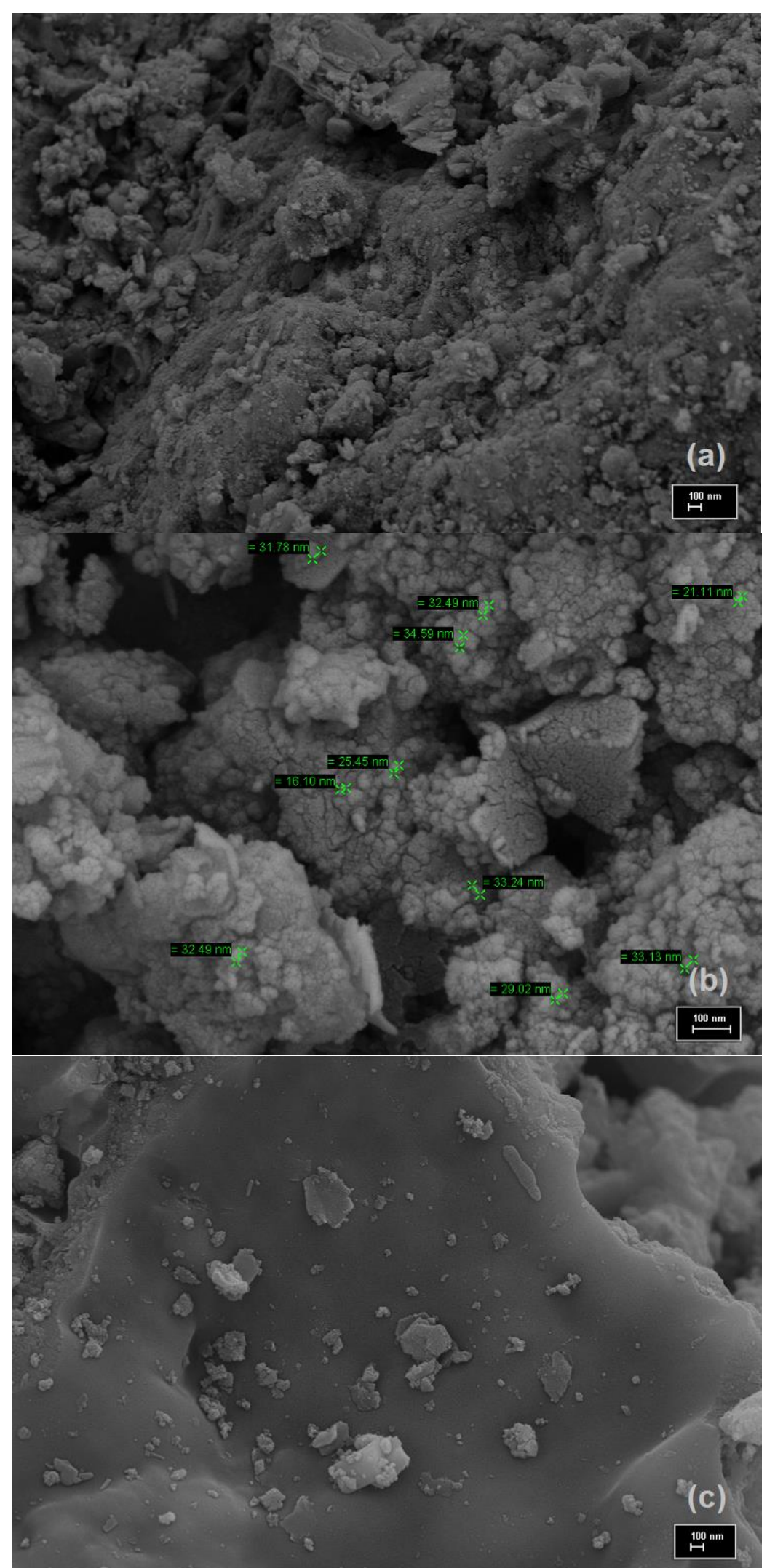

Şekil 1. Biyokömürün $100 \mathrm{~nm}$ ölçeğinde adsorpsiyon (a) - (b) öncesi ve sonrası (c) SEM görüntüleri

Biyokömürün EDX analiz sonuçları Şekil 2'de gösterilmiştir. Yapıda en fazla C elementinin bulunduğu doğrulanırken $\mathrm{O}$ ve $\mathrm{Si}$ elementlerinin de olduğu tespit edilmiştir. 


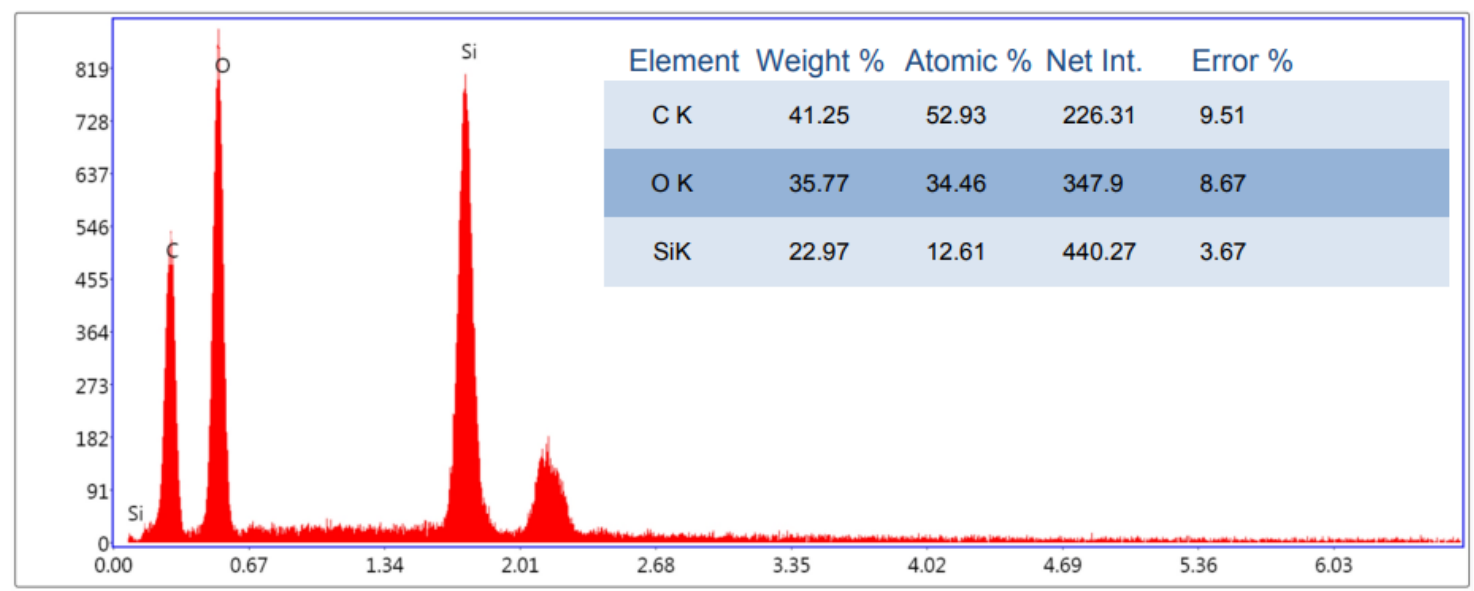

Lsec: 29.70 Cnts 0.000 keV Det: Octane Pro Det

Şekil 2. Biyokömürün EDX spektrumu

Şekil 3'te biyokömürün FT-IR sonuçları gösterilmiştir. Burada, yaklaşık $3600 \mathrm{~cm}^{-1} \mathrm{de}$ gözlenen geniş bantlar, biyokömürün hidroksil gruplarından uzanan serbest -OH gruplarını işaret etmiştir.

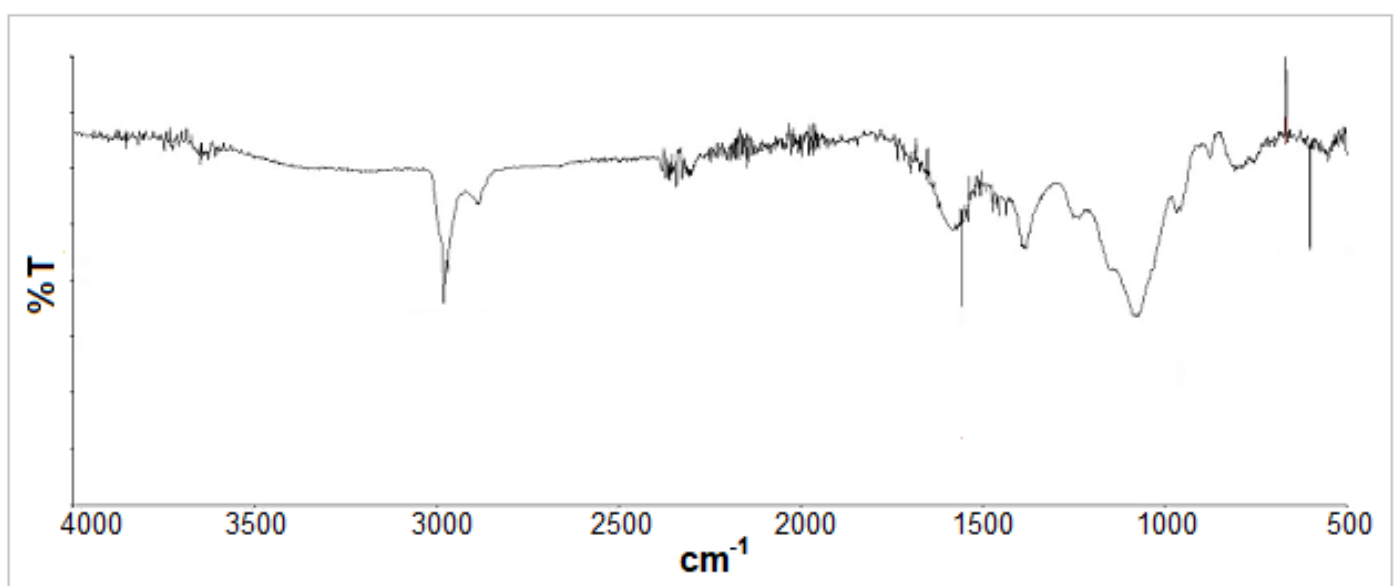

Şekil 3. Biyokömürün FT-IR spektrumu

$3000 \mathrm{~cm}^{-1}$ civarındaki bant aromatik -C-H esneme titreşimini göstermiştir. $1559 \mathrm{~cm}^{-1}$, de aromatik halkaların C-C germe titreşimi gözlenirken $1600 \mathrm{~cm}^{-1}$, deki bantta $\mathrm{C}=\mathrm{C}$ aromatik esneme ve halka deformasyon titreşimleri tespit edilmiştir. $1252 \mathrm{~cm}^{-1}$, deki bantlar fenoliklerin -OH gerilme titreşimini göstermiştir.

Biyokömürün kimyasal bileşimini incelemek için yapılan XRF sonuçları Tablo 4'te verilmiştir. Tablo incelendiğinde, biyokömürün $\mathrm{MgO}, \mathrm{Al}_{2} \mathrm{O}_{3}$ ve $\mathrm{Fe}_{2} \mathrm{O}_{3}$ gibi farkl1 yüzdelerde bileşiklere sahip olduğu görülmüş ve yapısında en fazla \%24,266 $\mathrm{SiO}_{2}$ ile $\% 8,568 \mathrm{CaO}$ bileşiklerinin bulunduğu belirlenmiştir.

Tablo 4. Biyokömürün XRF Sonuçları

\begin{tabular}{ccccccccccc}
\hline Element & $\mathbf{N a}_{2} \mathbf{O}$ & $\mathbf{M g O}$ & $\mathbf{A l}_{\mathbf{2}} \mathbf{O}_{\mathbf{3}}$ & $\mathbf{S i O}_{2}$ & $\mathbf{P}_{\mathbf{2}} \mathbf{O}_{\mathbf{5}}$ & $\mathbf{K}_{\mathbf{2}} \mathbf{O}$ & $\mathbf{C a O}$ & $\mathbf{M n O}$ & $\mathbf{F e}_{2} \mathbf{O}_{3}$ & $\mathbf{T i O}_{2}$ \\
\hline & $\%$ & $\%$ & $\%$ & $\%$ & $\%$ & $\%$ & $\%$ & $\%$ & $\%$ & $\%$ \\
Biyokömür & 2,450 & 0,802 & 1,093 & 24,266 & 2,380 & 4,835 & 8,568 & 0,113 & 1,051 & 0,091 \\
\hline
\end{tabular}

Sıfır yük noktası $\left(\mathrm{pH}_{\mathrm{pzc}}\right)$, adsorbentlerin yüzey yükünü gösterir ve yüzeyin net yükünün sıfır olduğu pH değeridir. Sıfır yük noktasının üzerindeki $\mathrm{pH}$ değerlerinde, adsorbentin yüzeyi net bir negatif veya anyonik yüke sahiptir ve bu katyon çekiciliğini ve katyon 
değişim reaksiyonlarını teşvik etmektedir. Sıfır yük noktasının altındaki $\mathrm{pH}$ değerlerinde de, yüzey net bir pozitif yüke sahiptir ve anyonları çekerek anyon değişim reaksiyonlarına katılmaktadır [26]. Sonuç olarak, adsorbent yüzeyi ve kirletici molekülleri arasındaki elektrostatik etkileşim adsorbentin pHpzc değerine bağlıdır. Burada pHf değişimi, pHi'nin bir fonksiyonu olarak çizilmiş ve iki eğrinin kesişme noktası pHpzc olup 8,5 olarak hesaplanmıştır (Şekil 4).

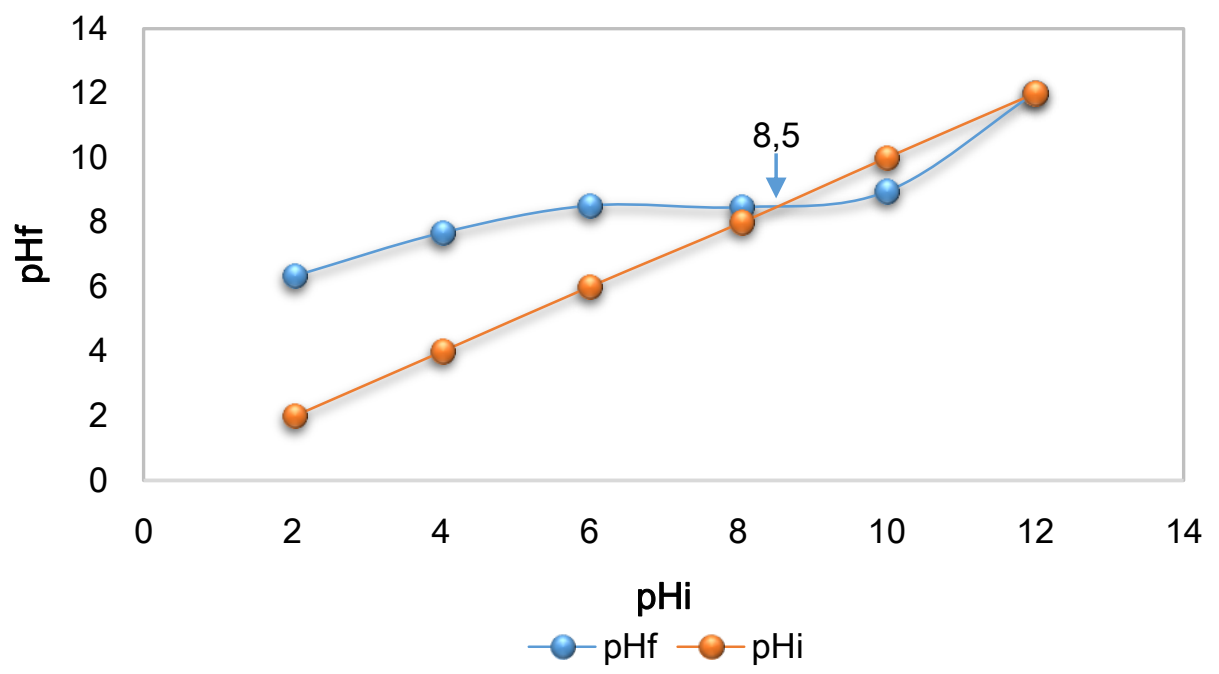

Şekil 4. Biyokömürün pHpzc ölçümü

5-Florourasilin $\mathrm{pK}_{\mathrm{a}}$ değeri 8,02' dir ve 5-FLU zayıf asit grubundadır (Tablo 1). Bu değer aynı zamanda izoelektrik noktasına karşılık gelmektedir. Dolayısıyla 5-FLU molekülü 8'in üzerindeki $\mathrm{pH}$ değerlerinde negatif yükle yüklenirken $\mathrm{pH}=6$ veya altında pratik olarak nötrdür [31]. Bu çalışmada $\mathrm{pH}$ parametresi ilgili bir ayarlama yapılmamıştır ancak biyokömürün pHpzc değeri 8,5 olduğu için yüzeyi daha yüksek pH değerlerinde negatif yükle yüklenecektir. Bu durumda, yüzeyin anyonik 5-FLU'yu iterek adsorpsiyonu azaltması beklenmektedir.

Literatür verilerinde, biyokömür yüzeyinin normalde negatif yüklü olduğu ve negatif yüklü anyonik organik bileşikler ile biyokömür arasındaki elektrostatik itmenin hidrojen bağını teşvik edebileceği belirtilmiştir [13,32-35]. Bu çalışmada da biyokömür yüzeyi ve 5-FLU molekülleri arasındaki etkileşimin H-bağı ile gerçekleşmesi daha olasıdır. Biyokömür yüzeyindeki polar gruplar ile 5-FLU üzerindeki elektronegatif atomlar arasında H-bağının oluşması, 5-FLU ile su arasındaki H-bağının kopması sonucu gerçekleşir. Bu da, 5-FLU'nun suda daha az çözünür olmasına ve biyokömür yüzeyi için daha büyük bir afinite göstermesine neden olur.

\subsection{5-FLU'nun adsorpsiyon sonuçları}

Box-Behnken deneysel tasarım yöntemine göre gerçekleştirilen 5-FLU'nun deneysel \% adsorpsiyon sonuçları Tablo 5'te gösterilmiştir. BBD ile sağlanan koşullarda, \% adsorpsiyonun 33,7 ile 93,4 arasında değiştiği tespit edilmiştir. En düşük adsorpsiyon yüzdesi, 15 dakikalık işlem süresinde, $15 \mathrm{mg} / \mathrm{L}$ 5-FLU konsantrasyonu için 0,5 g adsorbent kullanıldığında elde edilirken; en yüksek adsorpsiyon 37,5 dakikalık işlem süresinde, $5 \mathrm{mg} / \mathrm{L}$ 5-FLU konsantrasyonu için 2,0 $\mathrm{g}$ adsorbent kullanıldığında gerçekleşmiş̧ir. 
Tablo 5. 5-Florourasilin Box-Behnken Deneysel Tasarımından Elde Edilen Adsorpsiyon Sonuçları

\begin{tabular}{ccccc}
\hline & $\mathbf{x}_{\mathbf{1}}$ & $\mathbf{x}_{\mathbf{2}}$ & $\mathbf{x}_{\mathbf{3}}$ & Yanit \\
\hline Deney No & $\begin{array}{c}\text { Konsantrasyon } \\
(\mathbf{m g} / \mathbf{L})\end{array}$ & $\begin{array}{c}\text { Zaman } \\
(\mathbf{d k})\end{array}$ & $\begin{array}{c}\text { Adsorbent } \\
(\mathbf{g})\end{array}$ & \begin{tabular}{c} 
Adsorpsiyon $(\boldsymbol{\%})$ \\
\hline 1
\end{tabular} \\
\hline & 5 & 15 & 1,25 & 87,4 \\
3 & 25 & 15 & 1,25 & 69,6 \\
4 & 5 & 60 & 1,25 & 91,9 \\
5 & 25 & 60 & 1,25 & 74,8 \\
6 & 5 & 37,5 & 0,5 & 47,2 \\
7 & 25 & 37,5 & 0,5 & 34,8 \\
8 & 5 & 37,5 & 2 & 93,4 \\
9 & 25 & 37,5 & 2 & 66,3 \\
10 & 15 & 15 & 0,5 & 33,7 \\
11 & 15 & 60 & 0,5 & 44,4 \\
12 & 15 & 15 & 2 & 65,9 \\
13 & 15 & 60 & 2 & 83,1 \\
14 & 15 & 37,5 & 1,25 & 78,5 \\
15 & 15 & 37,5 & 1,25 & 77,3 \\
16 & 15 & 37,5 & 1,25 & 77,9 \\
17 & 15 & 37,5 & 1,25 & 76,8 \\
\hline & 15 & 37,5 & 1,25 & 78 \\
\hline
\end{tabular}

Tablo 5 incelendiğinde, 5-Florourasilin konsantrasyonu arttıkça \% adsorpsiyonun azaldığı gözlenmiştir. Bununla birlikte, zaman ve adsorbent miktarı arttıkça \% adsorpsiyon da artış göstermiştir.

Deneysel tasarım çalışmalarında elde edilen verilere göre deneysel sonuçlara etki eden parametrelerin etki değerlerinin hesaplanması ve hipotez testlerinin kontrol edilmesi için varyans analizi (ANOVA) kullanılmıştır. Modelin uyumu, $\mathrm{R}^{2}$ ve düzeltilmiş $\mathrm{R}^{2}$ katsayılarıyla değerlendirilirken, modelin anlamlılığ 1 ve yeterliliği Fisher varyasyon oranı $(\mathrm{F})$ ve olasılık değerinden $(\mathrm{p}<0,05)$ belirlenmiştir [12,18]. Adsorpsiyon çalışmalarından elde edilen verilerin varyans analiz sonuçları Tablo 6'da gösterilmiştir.

Tablo 6. 5-Florourasil için Adsorpsiyon Varyans Regresyon Modelinin Analizi

\begin{tabular}{lccccc}
\hline & $\begin{array}{c}\text { Kareler } \\
\text { Toplamı }\end{array}$ & df & $\begin{array}{c}\text { Ortalama } \\
\text { Kareler }\end{array}$ & F-Değeri & p-Değeri \\
\hline Model & 5529,03 & 9 & 614,34 & 83,39 & $<0,0001$ \\
A-Konsantrasyon & 691,92 & 1 & 691,92 & 93,92 & $<0,0001$ \\
B-Zaman & 176,72 & 1 & 176,72 & 23,99 & 0,0018 \\
C-Adsorbent & 2760,24 & 1 & 2760,24 & 374,67 & $<0,0001$ \\
AB & 0,12 & 1 & 0,12 & 0,02 & 0,9010 \\
AC & 54,02 & 1 & 54,02 & 7,33 & 0,0303 \\
BC & 10,56 & 1 & 10,56 & 1,43 & 0,2701 \\
A $^{2}$ & 49,75 & 1 & 49,75 & 6,75 & 0,0355 \\
B $^{2}$ & 0,19 & 1 & 0,19 & 0,03 & 0,8769 \\
C $^{2}$ & 1806,35 & 1 & 1806,35 & 245,19 & $<0,0001$ \\
Artık & 51,57 & 7 & 7,37 & & \\
Uyum Eksikliği & 49,83 & 3 & 16,61 & 38,18 & 0,0021 \\
Teorik Hata & 1,74 & 4 & 0,44 & & \\
Toplam & 5580,60 & 16 & & & \\
\hline
\end{tabular}


ANOVA verilerine göre 5-FLU için elde edilen korelasyon, $\mathrm{R}^{2}=0,9908$ olarak hesaplanmıştır. $\mathrm{R}^{2}$ değerinin 1'e yakın olması iyi bir korelasyon sağlandığını ve modelin güvenilirliğini göstermiştir. Benzer şekilde, düzeltilmiş $\mathrm{R}^{2}=0,9789$ de modelin her bir bağımsız değişkenin etkisini karşılaştırmadaki başarısını göstermiştir. Varyans katsayısı (CV) 3,91 olarak belirlenmiştir. Bu durum yine yüksek hassasiyet ile güvenilir verileri işaret etmiştir.

F değerinin 83,39 'dan büyük olması modelin önemli olduğunu göstermiş ve gürültü nedeniyle bu kadar büyük bir F değerinin oluşma olasılığının yalnızca \% 0,01 olduğu belirlenmiştir. $\mathrm{P}$ değerinin de 0,05 'den küçük olması, model terimlerinin anlamlı olduğunu göstermiş ve bu durumda $\mathrm{A}, \mathrm{B}, \mathrm{C}, \mathrm{AC}, \mathrm{A}^{2}, \mathrm{C}^{2}$ 'nin önemli model terimleri olduğu tespit edilmiştir. 0,10 'den büyük değerler model terimlerinin önemli olmadığını ifade etmiştir.

ANOVA'da yeterli kesinlilik değeri sinyal-gürültü oranını ölçmekte ve bu değerin 4'ten büyük olması istenmektedir. Yapılan deneysel çalışmalar sonucunda yeterli kesinlik değeri 5-FLU için 28,6420 olarak hesaplanmıştır.

Maksimum adsorpsiyon kapasitesi için elde edilen optimum koşullar 5-FLU konsantrasyonu için 5,48 mg/L, zaman için 39,61 dk ve adsorbent miktarı için 1,61 g/L olarak belirlenmiş ve burada \%95,99 giderim sağlanmıştır.

Box-Behnken tasarım çalışmalarına göre ortaya çıkan model denklemi (Denklem 3) aşağıda verilmiştir:

$$
\begin{aligned}
Y(\% \text { Ads })= & 77,70-9,30 x_{1}+4,70 x_{2}+18,58 x_{3}+0,1750 x_{1} x_{2} \\
& -3,68 x_{1} x_{3}+1,62 x_{2} x_{3}+3,44 x_{1}^{2}-0,2125 x_{2}^{2}-20,71 x_{3}^{2}
\end{aligned}
$$

Denklem 3 incelendiğinde, konsantrasyon $\left(\mathrm{x}_{1}\right)$ katsayısının negatif olduğu belirlenmiş ve bu durumda konsantrasyon arttıkça adsorpsiyonun azaldığ 1 ifade edilmiştir. Bununla birlikte, zaman $\left(\mathrm{x}_{2}\right)$ ve adsorbent $\left(\mathrm{x}_{3}\right)$ katsayılarının pozitif olduğu belirlenmiş ve burada da zaman ve adsorbent miktarı arttıkça adsorpsiyonun arttığı tespit edilmiştir. Sonuçta, denklemde yer alan parametrelerin başındaki katsayı ne kadar büyükse o oranda adsorpsiyonu etkilediği $\left(\mathrm{x}_{3}>\mathrm{x}_{2}>\mathrm{x}_{1}\right)$ ve burada en fazla etki eden parametrenin 18,58 katsayısı ile adsorbent olduğu belirlenmiştir.

Box-Behnken deneysel tasarım yönteminin adsorpsiyon deneyleriyle uyumlu olduğu aşağıda verilen Şekil 5, Şekil 6 ve Şekil 7'deki grafikler ile doğrulanmıştır. 


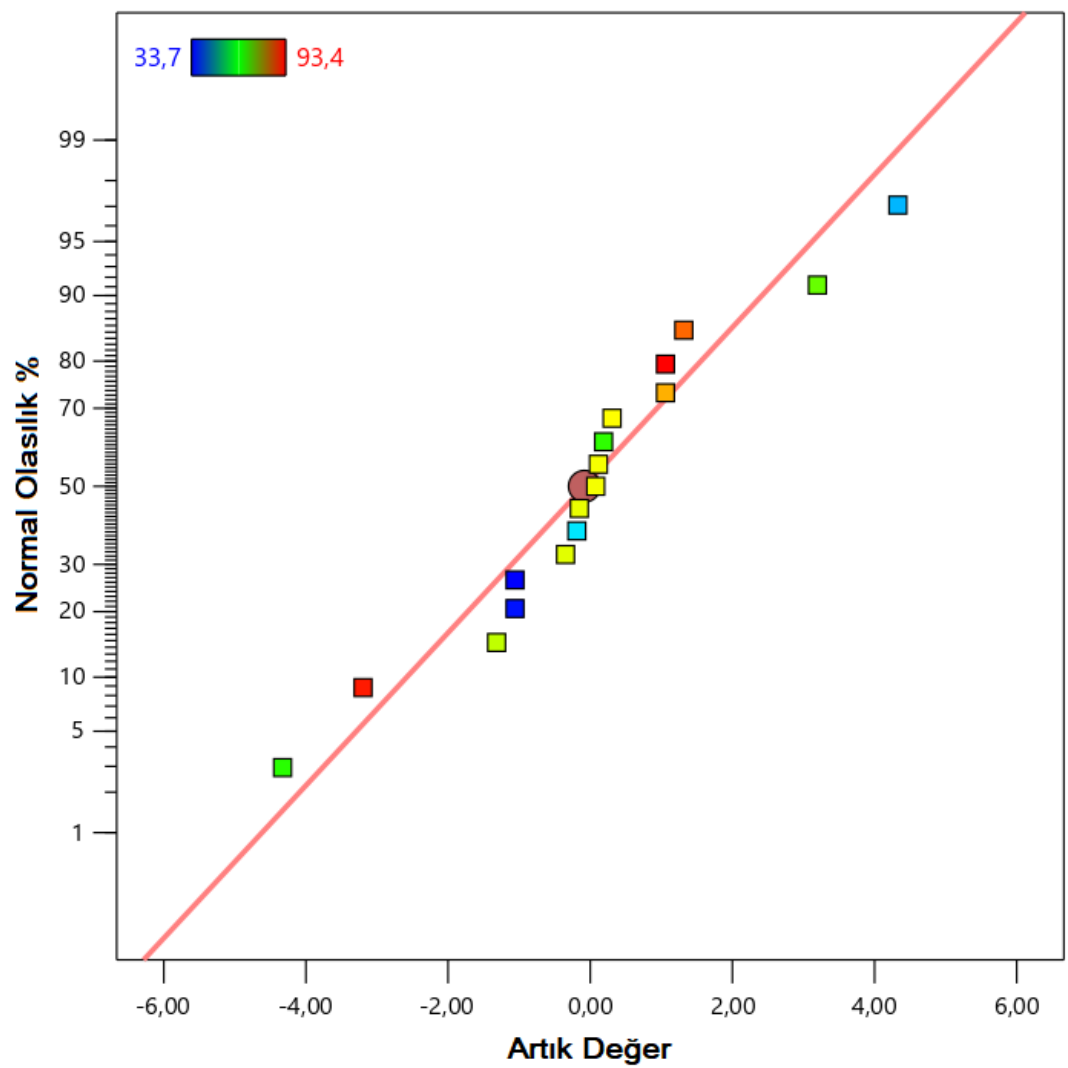

Şekil 5. 5-Florourasil için artık değerlerin normal olasılık grafiği

Şekil 5'teki artık değerlerin normal olasılık grafiği incelendiğinde, değerlerin kalibrasyon çizgisine yakın ve çizginin üzerinde olduğu gözlemlenmiş ve bu sayede gerçek değerlerin normal dağılım izlediği belirlenmiştir.

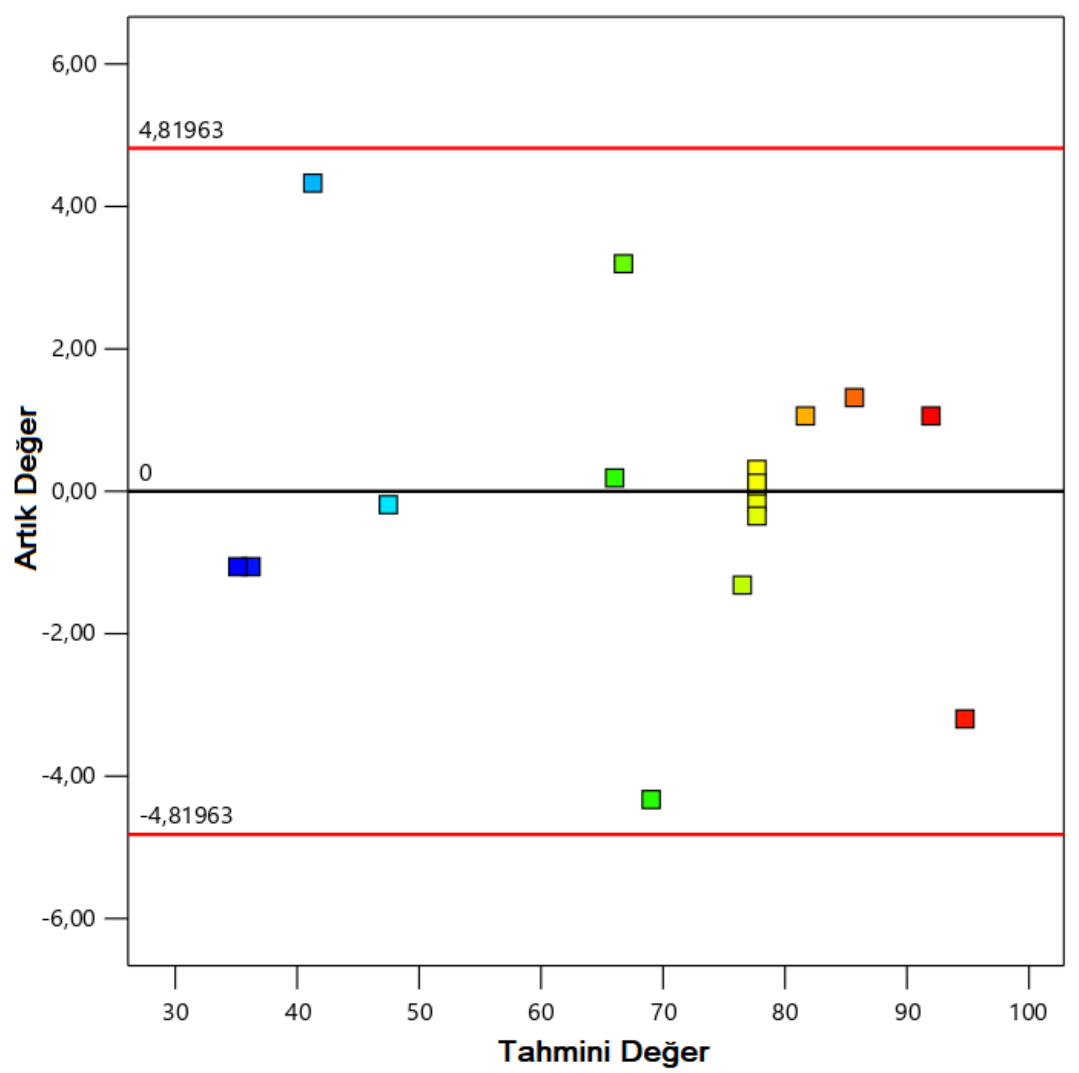

Şekil 6. 5-Florourasil için artık değerlerin - tahmini değer grafiği 
Şekil 6'daki artık değer - tahmini değer grafiğinde, değerlerin sıfır çizgisine yaklaştıkça sapmaları azalttığ ifade edilmiştir.

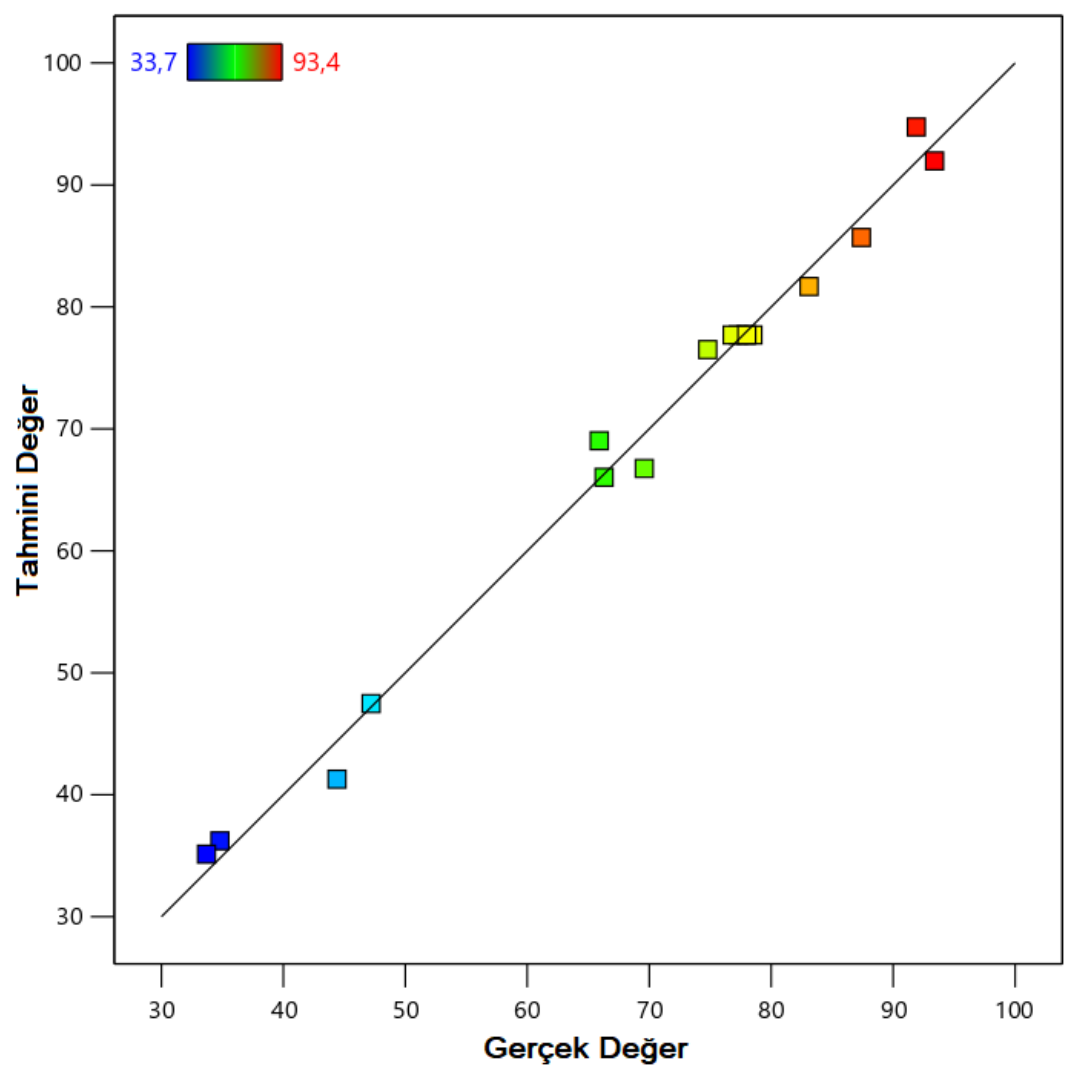

Şekil 7. 5-Florourasil için tahmini değerlerin - gerçek değer grafiği

Şekil 7'deki grafikte de gerçek ve tahmini değerlerin çok fazla dağılmadığı görülmüş ve bu değerlerin yaklaşık tutarlı olduğu belirlenmiştir.

Denklem 3'te yer alan deneysel faktörlerin 5-Florourasilin ultrasonik ortamdaki adsorpsiyonu üzerine etkilerini göstermek için deneylerden elde edilen verilerin üç boyutlu grafikleri çizilmiş ve Şekil 8, Şekil 9 ve Şekil 10'da gösterilmiştir. 


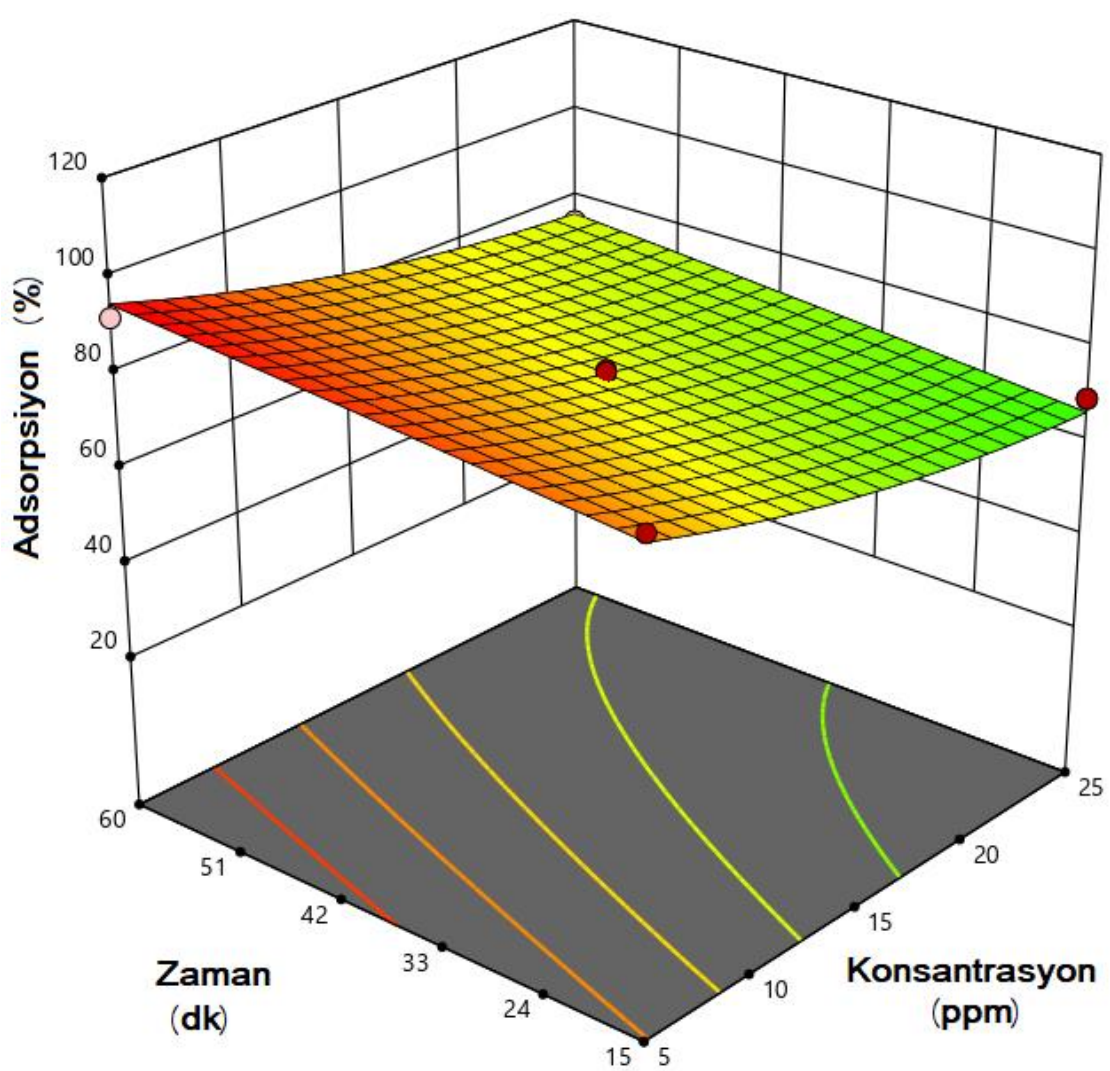

Şekil 8. Zaman ve konsantrasyon faktörlerinin 5-Florourasilin adsorpsiyon sürecine etkisi

Şekil 8'deki grafikte zaman ve konsantrasyonun \% adsorpsiyon verimi üzerine etkisi incelenmiştir. Grafiğe göre, adsorbent miktarı ve zaman sabit tutulup konsantrasyon 5 ppm'den 25 ppm'e arttırıldığında adsorpsiyonun \%91,90'den \%74,80'e düştüğü tespit edilmiştir. Adsorbent miktarı ve konsantrasyon sabit tutulup zaman 15 dakikadan 60 dakikaya arttırıldığında adsorpsiyonun \%87,40'den \%91,90'a yükseldiği gözlemlenmiştir. Burada, konsantrasyonun artması ile adsorbent yüzeyine tutunacak 5FLU molekül sayısının artmasından dolayı \% adsorpsiyonu azalttı̆̆ı belirlenmiştir. Zamanın artması ile adsorpsiyonun artması da, muhtemelen, adsorbentin yüzeyinde kütle transferini teşvik eden ve aynı zamanda çözünen moleküllerin dağılımını artıran ultrasonik dalgaların kullanımından kaynaklanmıştır. Sonuç olarak, zaman faktörünün pozitif etki gösterdiği ve \% adsorpsiyonu arttırdığ 1 tespit edilmiştir. 


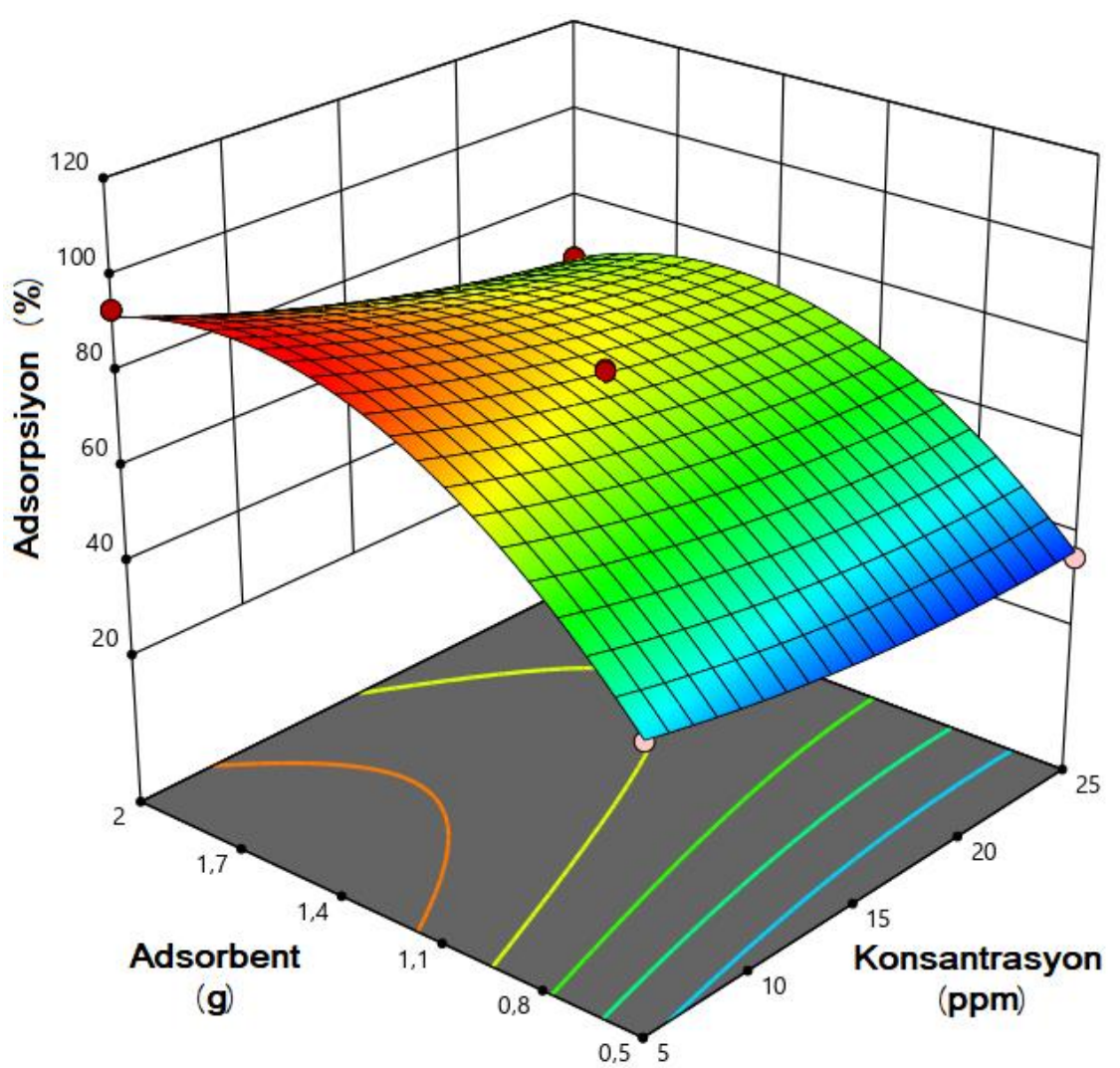

Şekil 9. Adsorbent ve konsantrasyon faktörlerinin 5-Florourasilin adsorpsiyon sürecine etkisi

Şekil 9'da verilen grafikte adsorbent ve konsantrasyon faktörlerinin \% adsorpsiyon üzerine etkileri incelenmiştir. Konsantrasyon ve zaman sabit tutulup adsorbent miktarı $0,5 \mathrm{~g} / \mathrm{L}$ 'den 2,0 g/L'ye arttırıldığında adsorpsiyonun \%47,20'den \%93,40'a arttı̆̆ 1 tespit edilirken zaman ve adsorbent miktarı sabit tutulup konsantrasyon 5 ppm'den 25 ppm'e arttırıldığında adsorpsiyonun \%47,20'den \%34,80'e düştüğü belirlenmiştir. Burada adsorbent miktarının artması ile \% adsorpsiyon önemli derecede artarken, konsantrasyonun artması ile \% adsorpsiyon azalmıştır.

Literatürde, organik bileşiklerin adsorpsiyonunun nispeten düşük çözünen konsantrasyonlarında veya düşük uçucu madde içeriğine sahip biyokömürlerde gerçekleştirilmesinde gözenek doldurma mekanizmalarının etkin olduğu bildirilmiştir $[30,34]$. Burada, adsorbent miktarı ile \% adsorpsiyonun artmasının sebebi, adsorbentin 5-Florourasil ile etkileşime girecek yüzey alanının artması sonucu aynı miktardaki 5Florourasil molekülünün daha fazla adsorbent yüzeyine dağılmasıdır. Bununla birlikte, adsorbent miktarının artması ile adsorpsiyon belli bir noktaya kadar artmakta ve bu noktadan sonra adsorpsiyon sabitlenmektedir. Konsantrasyon arttıkça \% adsorpsiyonun azalması da, adsorbent yüzeyine tutunacak 5-Florourasil molekül sayısının artmasından ve belirli bir süre sonra adsorbent yüzeyindeki mevcut gözeneklerin doygunluğundan kaynaklanmaktadır. 


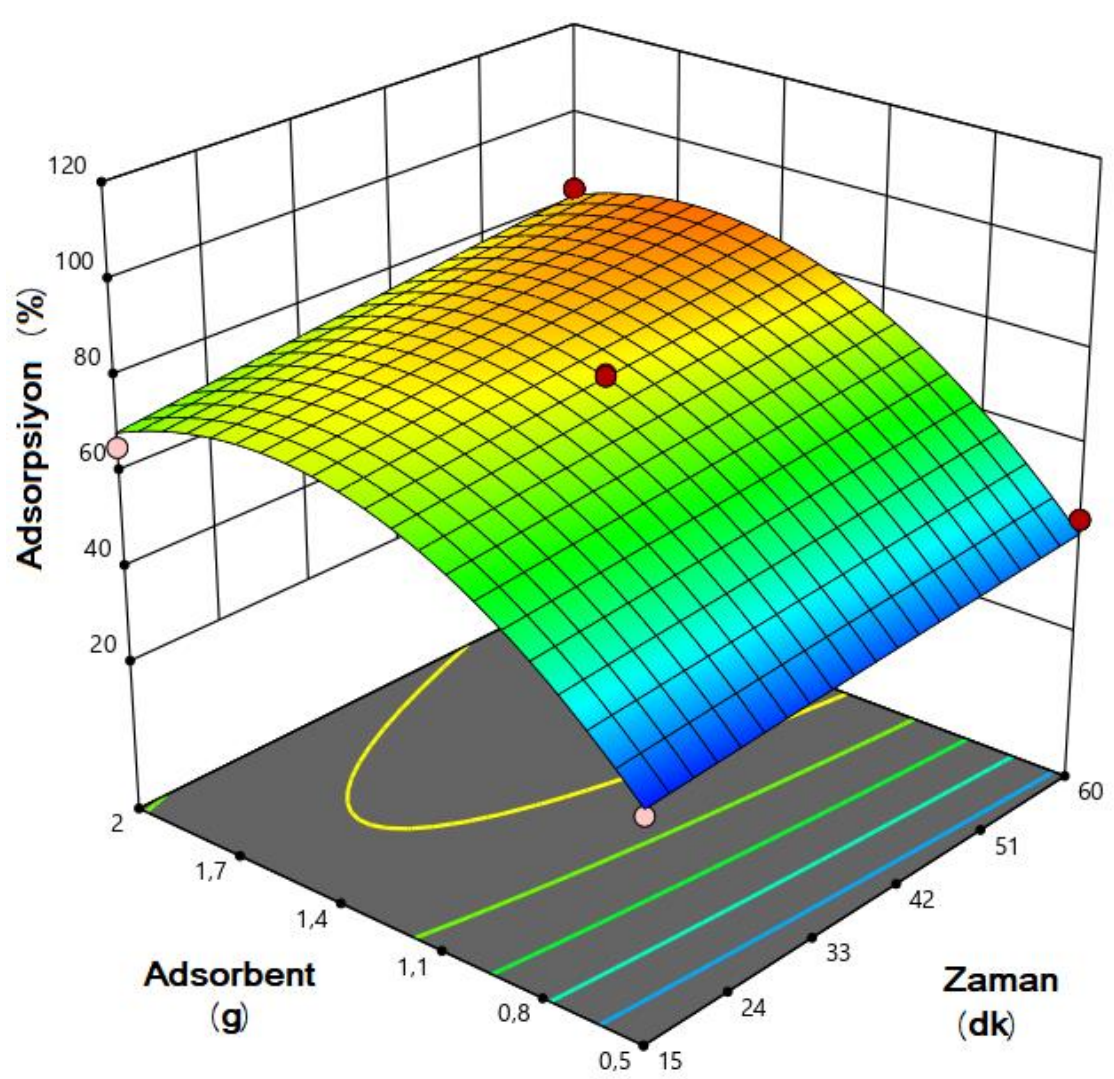

Şekil 10. Adsorbent ve zaman faktörlerinin 5-Florourasilin adsorpsiyon sürecine etkisi

Şekil 10'da verilen grafikte hem zamanın hem de adsorbent miktarının \% adsorpsiyon verimi üzerine etkisi incelenmiştir. Konsantrasyon ve adsorbent miktarı sabit tutulup zaman 15 dakikadan 60 dakikaya arttırıldığında adsorpsiyonun \%33,70'den \%44,40'a yükseldiği gözlemlenmiştir. Benzer şekilde, konsantrasyon ve zaman sabit tutulup adsorbent miktarı 0,5 g'dan 2,0 g'a arttırıldığında adsorpsiyonun \%44,40'dan \%83,10'a arttığ1 tespit edilmiştir. Burada zaman faktörünün adsorbent faktörü yanında pozitif etki göstermesine rağmen daha az etkin olduğu ve adsorbent miktarının \% adsorpsiyonu daha fazla arttırdığg belirlenmiştir.

Literatür verilerinde, yüksek $\mathrm{Ca}, \mathrm{K}$ ve $\mathrm{Mg}$ konsantrasyonlarının adsorbent ile adsorbat arasındaki spesifik katyon- $\pi$ etkileşimlerini teşvik ettiği ve aromatik bileşiklerin adsorpsiyonunu artırabildiği belirtilmiştir [20,36]. Benzer şekilde, anyonik organik bileşiklerin mineral açısından zengin biyokömürlerin pozitif yüklü yüzeylerine bağlanarak adsorplanabileceği ifade edilmiştir [13]. Kullanılan biyokömürdeki yüksek $\mathrm{Ca}$ ve $\mathrm{K}$ içeriğinin 5-FLU'nun adsorpsiyonunda pozitif etki gösterdiği düşünülmüştür. Ek olarak burada, biyokömür yüzeyi ve 5-FLU molekülleri arasındaki etkileşimin hidrojen bağı ile gerçekleşmesi daha olasıdır. Biyokömürlerde bol miktarda bulunan polar grupların, su emilimini kolaylaştırdığı ve biyokömür ile elektronegatif elementler içeren organik bileşikler arasında H-bağ oluşumunu desteklediği bildirilmiştir [32,34]. Sonuçta, polar 5-FLU'nun adsorpsiyonu literatürde bildirilen aktif karbonlara kıyasla işlem görmemiş biyokömür ile başarılı bir şekilde gerçekleştirilmiştir.

\subsection{Adsorpsiyon izotermi}

Denge durumundaki 5-FLU - adsorbent ilişkisi, deneysel veriler Langmuir ve Freundlich izoterm modellerine uydurularak araştırılmıştır. Langmuir izotermi, belirli 
sayıda adsorpsiyon bölgesi içeren bir yüzeye tek tabakalı adsorpsiyonu varsaymakta ve aşağıdaki Denklem 4 ile açıklanmaktadır.

$$
\frac{C_{e}}{q_{e}}=\frac{1}{b q_{\max }}+\frac{C_{e}}{q_{\max }}
$$

qe, dengede adsorbent miktarı başına adsorbe edilen madde miktarını temsil etmektedir $(\mathrm{mg} / \mathrm{g}) . \quad b$ ve $\mathrm{q}_{\max }$ terimleri sirasıyla adsorpsiyon bağlama sabiti ve maksimum adsorpsiyon kapasitesidir ve değerleri grafiğin eğiminden ve kesişmesinden elde edilmektedir.

Freundlich izotermi, yüzeylerin farklı afinitelere (heterojen) sahip adsorpsiyon alanlarından oluşması temelinde adsorpsiyonu tanımlayan deneysel bir modeldir. Deneysel veriler, aşağıda gösterilen Freundlich denkleminin logaritmik formuna uygulanmıştır (Denklem 5).

$$
\ln q_{e}=\ln K_{f}-\frac{1}{n} \ln C_{e}
$$

Burada $\mathrm{K}_{f}$, adsorbent için adsorbatın afinitesini yansıtan bir parametredir ve $1 / n$, heterojenliği yansitan boyutsuz bir parametredir. $n$ değeri ne kadar yüksekse, adsorbentin heterojenliği o kadar büyüktür.

Denge durumundaki 5-FLU ve biyokömür ilişkisi, deneysel verilerin Langmuir ve Freundlich izoterm modellerine benzetilmesiyle daha ayrıntılı incelenmiştir. Bu modellerin dayandığ temeller ve ilgili denklemleri literatürde kapsamlı olarak açıklanmıştır [37-39]. İzoterm sabitleri ve deneysel verilerle korelasyon katsayıları Tablo 7'de listelenmiştir. Langmuir izotermi ve Freundlich izotermi birbirine oldukça benzer uyum göstermiştir (korelasyon katsayısıları sırasıyla $R^{2}=0,999$ ve $R^{2}=0,992$ ). Maksimum adsorpsiyon kapasitesi $5,75 \mathrm{mg} / \mathrm{g}$ olarak bulunmuştur. $1 / \mathrm{n}$, heterojenliği yansitan boyutsuz bir parametre olup 0,89 değeriyle uygun adsorpsiyonu göstermiştir.

Tablo 7. Adsorpsiyon İzotermi Parametreleri

\begin{tabular}{cccccc}
\hline & $\mathbf{q}_{\max }(\mathbf{m g} / \mathbf{g})$ & $\mathbf{b}(\mathbf{L} / \mathbf{m g})$ & $\mathbf{R}^{2}$ & $\mathbf{K}_{\mathbf{f}}$ & $\mathbf{n}$ \\
\hline Langmuir & 5,75 & 2,93 & 0,999 & - & 1,11 \\
Freundlich & - & 0,802 & 0,992 & 4,30 & 2,380 \\
\hline
\end{tabular}

\subsection{Adsorpsiyon kinetiği}

Biyokömür ile 5-FLU'nun sulu çözeltiden adsorpsiyonu, dinamik olarak kinetik modeller kullanılarak ve kimyasal emilim, difüzyon kontrolü ve kütle transferi gibi adsorpsiyon işleminin hız kontrol mekanizması incelenerek çalışılmıştır. 5-FLU'nun adsorpsiyon kinetiğini açiklamak için uygulanan matematiksel modeller pseudo birinci dereceden (Lagergren modeli), pseudo ikinci dereceden kinetik modelleridir. 5FLU'nun adsorpsiyon mekanizmasını incelemek için, bu kinetik modellerin doğrusallaştırılmış denklemleri uygulanmış ve sonuçlar Şekil 11'de gösterilmiştir.

Pseudo birinci dereceden kinetik model, adsorbatın basit bir yüzey fiziksel adsorpsiyonunu varsaymakta ve aşağıdaki denklemle (Denklem 6) açıklanmaktadır. 


$$
\ln \left(q_{e}-q_{t}\right)=\ln \left(q_{e}\right)-k_{A} t
$$

$\mathrm{q}_{\mathrm{e}}$ ve $\mathrm{q}_{\mathrm{t}}$, sırasıyla dengede ve $\mathrm{t}$ zamanında biyokömür (mg (5-FLU) / g (biyokömür) cinsinden) üzerine adsorbe edilen 5-FLU miktarıdır ve $\mathrm{k}_{A}$, adsorpsiyon için pseudo birinci dereceden modelin hız sabitidir [40]. $\mathrm{q}_{\mathrm{e}}$ ve $\mathrm{k}_{A}$ değerleri, $\ln$ (qe - qt) 'nin zamana karşı çizilen doğrusal grafiğinin kesişiminden ve eğiminden elde edilebilmektedir (Şekil $11)$.

\section{Pseudo Birinci Derece}

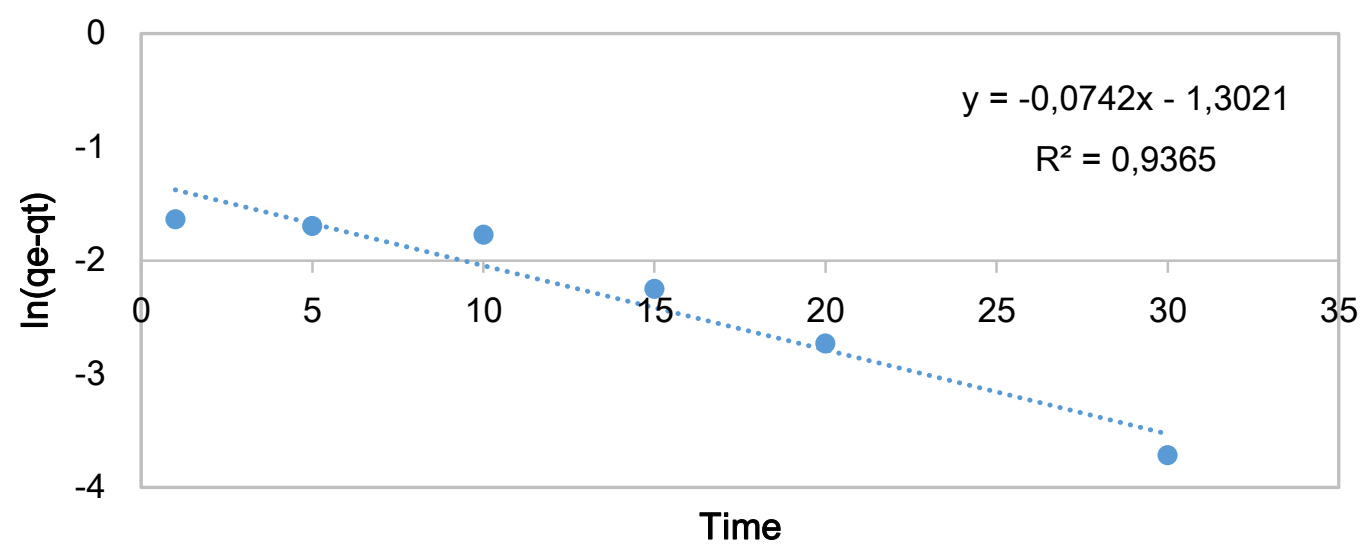

Pseudo İkinci Derece

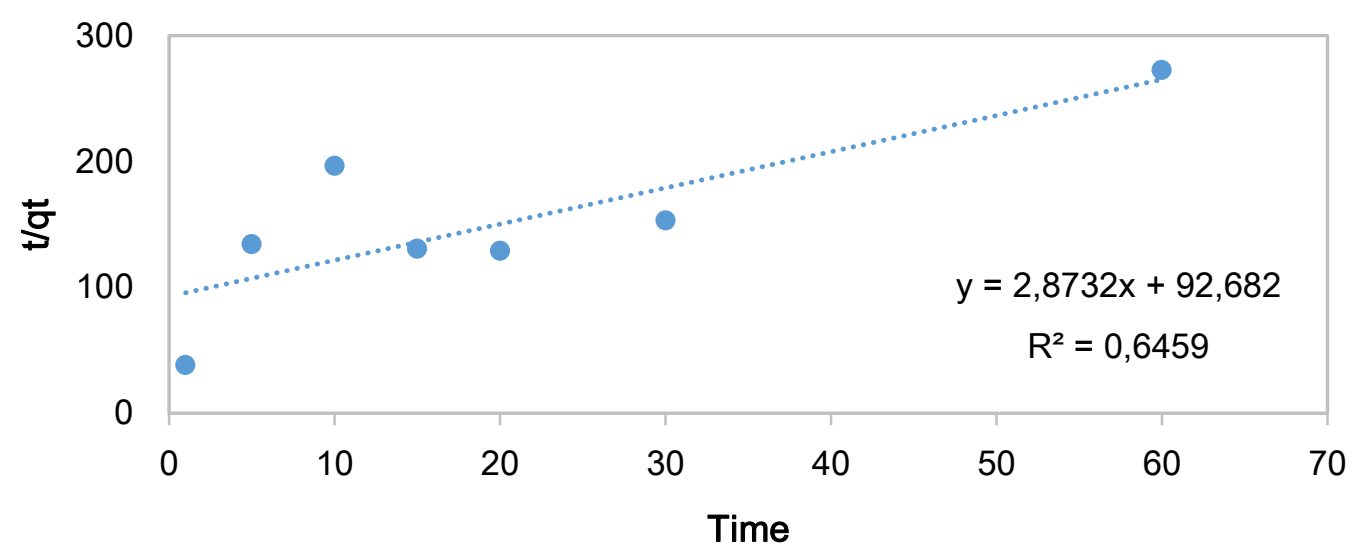

Şekil 11. Pseudo birinci derece ve Pseudo ikinci derece modelin doğrusallaştırılmış grafiği

Adsorpsiyon mekanizması pseudo ikinci dereceden bir kinetiği takip ederse, hız sınırlama adımı, adsorban ve adsorbat arasında elektronların paylaşımı veya değişimi yoluyla valans kuvvetlerini içeren kimyasal adsorpsiyon olacaktır. Pseudo ikinci dereceden kinetik matematiksel olarak aşağıdaki denklemle (Denklem 7) tanımlanmaktadır.

$$
\frac{t}{q_{t}}=\frac{1}{k_{B} q_{e}^{2}}+\frac{t}{q_{e}}
$$

Burada $\mathrm{q}_{\mathrm{t}}$ ve $\mathrm{q}_{\mathrm{e}}$ yukarıdaki gibi tanımlanır ve $\mathrm{k}_{B}$ hız sabitidir (g/mg dk). t/q 'nun t'ye karşı çizilen doğrusal grafiğinin eğimi ve kesişimi, sırasıyla qe ve $\mathrm{k}_{B}$ değerlerini 
belirlemiştir (Şekil 11). Her modele karşılık gelen özellikler ve sabitler Tablo 8'de gösterilmiştir.

Tablo 8. Pseudo-Birinci Derece ve Pseudo-Ikinci Dereceden Modellerin Parametreleri

\begin{tabular}{lll}
\hline Kinetik model & Parametre & Değer \\
\hline Pseudo-birinci derece & $\mathrm{q}_{\mathrm{e}}$, deneysel $(\mathrm{mg} / \mathrm{g})$ & 0,220 \\
& $\mathrm{q}_{\mathrm{e}}$, hesaplanan $(\mathrm{mg} / \mathrm{g})$ & 0,231 \\
& $\mathrm{k}_{\mathrm{A}}\left(\mathrm{dk}^{-1}\right)$ & 0,074 \\
& $\mathrm{R}^{2}$ & 0,9364 \\
Pseudo-ikinci derece & $\mathrm{q}_{\mathrm{e}}$, deneysel $(\mathrm{mg} / \mathrm{g})$ & 0,220 \\
& $\mathrm{q}_{\mathrm{e}}$, hesaplanan $(\mathrm{mg} / \mathrm{g})$ & 0,34 \\
& $\mathrm{k}_{\mathrm{B}}(\mathrm{g} / \mathrm{mg} \mathrm{dk})$ & 0,046 \\
& $\mathrm{R}^{2}$ & 0,6487 \\
\hline
\end{tabular}

Pseudo birinci dereceden kinetik modelin korelasyon katsayıs1 $\left(\mathrm{R}^{2}=0,9364\right)$, pseudo ikinci dereceye $\left(\mathrm{R}^{2}=0,6487\right)$ kıyasla veriler için daha iyi uyum sağlamıștır. Ek olarak, hesaplanan q değerinin deneysel değere yakın olduğu ve iyi eşleştiği gözlenmiştir. Bu da adsorpsiyon sürecinin pseudo birinci derece modeli izlediğini ve kemisorpsiyonun hız kontrol süreci olduğunu göstermiştir.

\section{Sonuç ve Yorum}

Son zamanlarda sularda tespit edilen ilaç kalıntıları diğer kirleticilere oranla çok düşük konsantrasyonlarda bulunsalar da biyolojik olarak parçalanması zor veya mümkün olmadığından çevre ve insan sağlığı üzerinde tehdit oluşturmuştur. Bu anlamda, zayıf biyolojik bozunma ve geleneksel atık su arıtma yöntemleriyle düşük giderim veriminden dolayı, bu kalıntıların başarılı bir şekilde ortamdan uzaklaştırılması için alternatif yöntemler geliştirilmiştir. Bununla birlikte, kalıntı konsantrasyonlarının çok düşük olduğu durumlarda bu yöntemlerin pahalı olduğu belirtilmiştir. Dolayısıyla daha etkili ve düşük maliyetli yöntemlere ihtiyaç duyulmuştur. Bu anlamda bu çalışmada, kemoterapide yaygın kullanılmasından ve çevrede toksik etkilere neden olmasından dolayı dikkat çeken 5-FLU'nun adsorpsiyonu için basit bir yöntem geliştirilmiştir.

5-Florourasilin ultrasonik ortamdaki adsorpsiyonu için kağıt çamuru ile buğday kabuğundan elde edilen biyokömürün kullanımı incelenmiştir. Box-Behnken tasarımıyla sağlanan koşullarda, \% adsorpsiyonun 33,7 ile 93,4 arasında değiştiği tespit edilmiştir. En düşük adsorpsiyon yüzdesi, 15 dakikalık işlem süresinde, $15 \mathrm{mg} / \mathrm{L}$ 5-FLU konsantrasyonu için $0,5 \mathrm{~g}$ adsorbent kullanıldığında elde edilirken; en yüksek adsorpsiyon 37,5 dakikalık işlem süresinde, $5 \mathrm{mg} / \mathrm{L}$ 5-FLU konsantrasyonu için 2,0 $\mathrm{g}$ adsorbent kullanıldığında gerçekleşmiştir. 5-FLU'nun konsantrasyonu arttıkça \% adsorpsiyonun azaldığ 1 gözlenirken, zaman ve adsorbent miktarı arttıç̧a \% adsorpsiyonun arttığı belirlenmiştir.

Deneysel tasarım çalışmalarında elde edilen modelin yeterliliğini ve katsayıların önemini vurgulamak için ANOVA kullanılmıştır. ANOVA sonuçları, çok düşük $p$ değeri $(\mathrm{p}<0,0001)$ ve F-testinden $(\mathrm{F}=83,39)$ de anlaşıldiğ 1 üzere modelin oldukça anlamlı olduğunu göstermiştir. $\mathrm{R}^{2}=0,9908$ değeri, deneysel veriler arasındaki uyumu gösterirken; düzeltilmiş $\mathrm{R}^{2}=0,9789$ oldukça yüksek bir değerle model için yüksek güvenilirlik göstermiştir. Maksimum adsorpsiyon kapasitesi için elde edilen optimum koşullar 5-FLU konsantrasyonu için 5,48 mg/L, zaman için 39,61 dk ve adsorbent miktarı için 1,61 g/L olarak belirlenmiş ve burada \%95,99 giderim sağlanmıştır. 
Denge çalışmaları izoterm modelleri kullanılarak yapılmış ve Langmuir modelinin deneysel verilere daha iyi uyum sağladığı belirlenmiştir. Langmuir izoterm modelinden elde edilen maksimum adsorpsiyon kapasitesi $5,75 \mathrm{mg} / \mathrm{g}$ olarak bulunmuştur. Sürecin kinetiği pseudo birinci dereceden olarak belirlenmiştir.

Sonuç olarak, adsorpsiyon sürecinde 5-FLU'nun sulu çözeltiden uzaklaştırılmasında en etkili parametrenin adsorbent olduğu belirlenmiştir. Biyokömürün yüksek maliyetli aktif karbonlara kıyasla herhangi bir işlem görmeden ve aktifleştirilmeden de etkili sonuçlar verdiği gözlemlenmiştir. Adsorbent olarak biyokömürün kullanılması, düşük maliyet ve yüksek verim gibi üstün özelliklere sahip olması yanında çevre kirliliğine sebep olan biyokütle atıklarının ortadan kaldırılması açısından da avantaj sağlamıştır. Bu yönüyle biyokömür gelecekteki çalışmalar için umut verici bir performans sergilemiş ve endüstriyel ölçeklerde de organik kirleticilerin düşük maliyetli adsorbentlerle giderilmesi için bir alternatif olmuştur.

\section{Araştırmacıların Katkı Oranı Beyanı}

Sema AKAY: Araştırma, Orijinal Taslak Yazımı, İnceleme ve Düzenleme.

\section{Destek ve Teşekkür Beyanı}

$\mathrm{Bu}$ çalışmanın yazarı olarak, desteklerinden dolayı Prof. Dr. Berkant Kayan'a çok teşekkür ederim.

\section{Çatışma Beyanı}

$\mathrm{Bu}$ çalışmanın yazarı olarak herhangi biriyle bir çatışma beyanım bulunmadığını bildiririm.

\section{Etik Kurul Onayı ve/veya Aydınlatılmış Onam Bilgileri}

$\mathrm{Bu}$ çalışmanın yazarı olarak herhangi bir etik kurul onayı ve aydınlatılıı̧ onam bilgileri beyanım bulunmadığını bildiririm.

\section{Kaynakça}

[1] M. Feng, R. Qu, X. Zhang, P. Sun, Y. Sui, L. Wang, and Z. Wang, "Degradation of flumequine in aqueous solution by persulfate activated with common methods and polyhydroquinone-coated magnetite/multi-walled carbon nanotubes catalysts," Water Res., 85, 1-10, 2015.

[2] B. Petrie, R. Barden, and B. Kasprzyk-Hordern, "A review on emerging contaminants in wastewaters and the environment: current knowledge, understudied areas and recommendations for future monitoring," Water Res., 72, 3-27, 2015.

[3] M. Governo, M. S. F. Santos, A. Alves, and L. M. Madeira, "Degradation of the cytostatic 5Fluorouracil in water by Fenton and photo-assisted oxidation processes," Environ. Sci. Pollut. Res., 24, 844-854, 2017.

[4] E. M. Siedlecka, "Removal of cytostatic drugs from water and wastewater: Progress in the development of advanced treatment methods," in Fate and Effects of Anticancer Drugs in the Environment, E. Heath, M. Isidori, T. Kosjek, and M. Filipič, Eds. Switzerland: Springer, Cham, 2020, pp. 197-219.

[5] S. Ndaw, F. Denis, P. Marsan, A. d'Almeida, and A. Robert, "Biological monitoring of occupational exposure to 5 -fluorouracil: urinary $\alpha$-fluoro- $\beta$-alanine assay by high performance liquid chromatography tandem mass spectrometry in health care personnel," J. Chromatogr. B Analyt. Technol. Biomed. Life Sci., 878 (27), 2630-2634, 2010.

[6] T. Kosjek, S. Perko, D. Zigon, and E. Heath, "Fluorouracil in the environment: Analysis, occurrence, degradation and transformation," J. Chromatogr. A, 1290, 62- 72, 2013.

[7] S. Zhan, Q. Zhao, S. Chen, J. Wang, Z. Liu, and C. Chen, "Solubility and partition coefficients of 5Fluorouracil in $\mathrm{ScCO}_{2}$ and $\mathrm{ScCO}_{2} /$ Poly(l-lactic acid)," J. Chem. Eng. Data, 59 (4), 1158-1164, 2014.

[8] A. Koltsakidou, M. Antonopoulou, E. Evgenidou, I. Konstantinou, A. E. Giannakas, M. Papadaki, D. Bikiaris, and D. A Lambropoulou, "Photocatalytical removal of fluorouracil using $\mathrm{TiO}_{2}-\mathrm{P} 25$ and N/S doped $\mathrm{TiO}_{2}$ catalysts: A kinetic and mechanistic study," Sci. Total Environ., 578, 257-267, 2017.

[9] J. Zhang, V. W. C. Chang, A. Giannis, and J-Y. Wang, "Removal of cytostatic drugs from aquatic environment: a review," Sci. Total Environ., 445-446, 281-298, 2013. 
[10] I. Ali, M. Asim, and T.A. Khan, "Low cost adsorbents for the removal of organic pollutants from wastewater,” J. Environ. Manag., 113, 170-183, 2012.

[11] N. Sivarajasekar, and R. Baskar, "Agriculture waste biomass valorisation for cationic dyes sequestration: a concise review," J. Chem. Pharm. Res., 7 (9), 737-748, 2015.

[12] Y. Zhou, L. Zhang and Z. Cheng, "Removal of organic pollutants from aqueous solution using agricultural wastes: A review," J. Mol. Liq., 212, 739-762, 2015.

[13] M. Ahmad, A. U. Rajapaksha, J. E. Lim, M. Zhang, N. Bolan, D. Mohan, M. Vithanage, S. S. Lee, and Y. S. Ok, "Biochar as a sorbent for contaminant management in soil and water: A review," Chemosphere, 99, 19-33, 2014.

[14] C. Wang, and H. Wang, "Pb(II) sorption from aqueous solution by novel biochar loaded with nanoparticles," Chemosphere, 192, 1-4, 2018.

[15] W. Xiang, X. Zhang, J. Chen, W. Zou, F. He, X. Hu, D. C. W. Tsang, Y. S. Ok, and B. Gao, "Biochar technology in wastewater treatment: A critical review," Chemosphere, 252, 126539, 2020.

[16] J.N. Sahu, J. Acharya, and B.C. Meikap, "Response surface modeling and optimization of chromium(VI) removal from aqueous solution using tamarind wood activated carbon in batch process," J. Hazard. Mater., 172 (2-3), 818-825, 2009.

[17] Z. Alam, S.A. Muyibi, and J. Toramae, "Statistical optimization of adsorption processes for removal of 2 4-dichlorophenol by activated carbon derived from oil palm empty fruit bunches," J. Environ. Sci., 19 (6), 674-677, 2007.

[18] K. P. Singh, S. Gupta, A. K. Singh, and S. Sinha, "Optimizing adsorption of crystal violet dye from water by magnetic nanocomposite using response surface modeling approach," J. Hazard. Mater., 186 (2-3), 1462-1473, 2011.

[19] F. N. Çatlıŏlu, S. Akay, B. Gözmen, E. Turunc, I. Anastopoulos, B. Kayan, and D. Kalderis, "Fe- modified hydrochar from orange peel as adsorbent of food colorant Brilliant Black: process optimization an kinetic studies," Int. J. Environ. Sci. Technol., 17, 1975-1990, 2020.

[20] D. Kalderis, B. Kayan, S. Akay, Esra Kulaks1z, and B. Gözmen, "Adsorption of 2,4-dichlorophenol on paper sludge/wheat husk biochar: Process optimization and comparison with biochars prepared from wood chips, sewage sludge and hog fuel/demolition waste," J. Environ. Chem. Eng., 5 (3), 2222-2231, 2017.

[21] L. Ioannou-Ttofa, and D. Fatta-Kassinos, "Cytostatic drug residues in wastewater treatment plants: Sources, removal efficiencies and current challenges," in Fate and Effects of Anticancer Drugs in the Environment, E. Heath, M. Isidori, T. Kosjek, and M. Filipič, Eds. Switzerland: Springer, Cham, 2020, pp. 103-138.

[22] L. Kovalova, D. R. U. Knappe, K. Lehnberg, C. Kazner, and J. Hollender, "Removal of highly polar micropollutants from wastewater by powdered activated carbon" Environ. Sci. Pollut. Res., 20, 3607-3615, 2013.

[23] M. Klavarioti, D. Mantzavinos and D. Kassinos, "Removal of residual pharmaceuticals from aqueous systems by advanced oxidation processes," Environ. Int., 35 (2), 402-417, 2009.

[24] S. Zhu, X. Huang, F. Ma, L. Wang, X. Duan, and S. Wang, "Catalytic removal of aqueous contaminants on N-doped graphitic biochars: inherent roles of adsorption and nonradical mechanisms," Environ. Sci. Technol., 52 (15), 8649-8658, 2018.

[25] S. Meyer, B. Glaser, and P. Quicker, "Technical, economical and climate related aspects of biochar production technologies: a literature review," Environ. Sci. Technol., 45 (22), 9473-9483, 2011.

[26] G. Newcombe, R. Hayes, and M. Drikas, "Granular activated carbon: importance of surface properties in the adsorption of naturally occurring organics," Colloids Surf. A Physicochem. Eng. Asp., 78, 65-71, 1993.

[27] A. Khataee, B. Kayan, D. Kalderis, A. Karimi, S. Akay, and M. Konsolakis, "Ultrasound-assisted removal of Acid Red 17 using nanosized $\mathrm{Fe}_{3} \mathrm{O}_{4}$-loaded coffee waste hydrochar," Ultrason. Sonochem., 35, 72-80, 2017.

[28] A. R. Bagheri, M. Ghaedi, A. Asfaram, A. A. Bazrafshan, and R. Jannesar, "Comparative study on ultrasonic assisted adsorption of dyes from single system onto $\mathrm{Fe} 3 \mathrm{O} 4$ magnetite nanoparticles loaded on activated carbon: experimental design methodology," Ultrason. Sonochem., 34, 294-304, 2017.

[29] H. J. Bachmann, T. D. Bucheli, A. Dieguez-Alonso, D. Fabbri, H. Knicker, H. P. Schmidt, et al., "Toward the standardization of biochar analysis: The COST action TD1107 interlaboratory comparison," J. Agric. Food Chem., 64 (2), 513-527, 2016.

[30] G. N. Kasozi, A. R. Zimmerman, P. Nkedi-Kizza, and B. Gao, "Catechol and humic acid sorption onto a range of laboratory-produced black carbons (biochars)," Environ. Sci. Technol., 44 (16), 6189-6195, 2010.

[31] V. Merino, A. López, Y. Kalia, and R. Guy, "Electrorepulsion versus electroosmosis: effect of pH on the iontophoretic flux of 5-Fluorouracil," Pharm. Res., 16 (5), 758-761, 1999. 
[32] K. Sun, M. Keiluweit, M. Kleber, Z. Pan, and B. Xing, "Sorption of fluorinated herbicides to plant biomass-derived biochars as a function of molecular structure," Bioresour. Technol.," 102 (21), 9897-9903, 2011.

[33] M. Teixido, J. J. Pignatello, J. L. Beltran, M. Granados, and J. Peccia, "Speciation of the ionizable antibiotic sulfamethazine on black carbon (biochar)," Environ. Sci. Technol., 45 (23), 10020-10027, 2011.

[34] M. Inyang, and E. Dickenson, "The potential role of biochar in the removal of organic and microbial contaminants from potable and reuse water: a review," Chemosphere, 134, 232-240, 2015.

[35] X. Tan, Y. Liu, G. Zeng, X. Wang, X. Hu, Y. Gu, and Z. Yang, "Application of biochar for the removal of pollutants from aqueous solutions," Chemosphere, 125, 70-85, 2015.

[36] S. Y. Oh, J. G. Son, and P. C. Chiu, "Biochar-mediated reductive transformation of nitro herbicides and explosives,” Environ. Toxicol. Chem., 32 (3), 501-508, 2013.

[37] M. Şener, B. Kayan, S. Akay, B. Gözmen, and D. Kalderis, "Fe-modified sporopollenin as a composite biosorbent for the removal of $\mathrm{Pb}^{2+}$ from aqueous solutions," Desal. Wat. Treat., 3994, 119, 2016.

[38] M. Dastkhoon, M. Ghaedi, A. Asfaram, A. Goudarzi, S. M. Langroodi, I. Tyagi, S. Agarwal, and V. K. Gupta, "Ultrasound assisted adsorption of malachite green dye onto $\mathrm{ZnS}$ : $\mathrm{Cu}$ - NP-AC: equilibrium isotherms and kinetic studies - response surface optimization," Sep. Purif. Technol., 156 (2), 780$788,2015$.

[39] I. Šafařik, Z. Maděrova, K. Pospišková, H.-P. Schmidt, E. Baldiková, J. Filip, M. Kř́̌žek, O. Malina, and M. Šafař́ková, "Magnetically modified biochar for organic xenobiotics removal," Water Sci. Technol., 74 (7), 1706-1715, 2016.

[40] A. A. Farghali, M. Bahgat, A. Enaiet Allah, and M. H. Khedr, "Adsorption of Pb(II) ions from aqueous solutions using copper oxide nanostructures," Beni-Suef Univ. J. Basic Appl. Sci., 2 (2), 61$71,2013$. 